\title{
Cell Signals Influencing Hepatic Fibrosis
}

\author{
Min Cong, Keiko Iwaisako, Chunyan Jiang, and Tatiana Kisseleva \\ Department of Medicine, School of Medicine, University of California, San Diego, La Jolla, CA 92093, USA \\ Correspondence should be addressed to Tatiana Kisseleva, tkisseleva@ucsd.edu
}

Received 1 March 2012; Accepted 1 June 2012

Academic Editor: Michael Ott

Copyright () 2012 Min Cong et al. This is an open access article distributed under the Creative Commons Attribution License, which permits unrestricted use, distribution, and reproduction in any medium, provided the original work is properly cited.

Liver fibrosis is the result of the entire organism responding to a chronic injury. Every cell type in the liver contributes to the fibrosis. This paper first discusses key intracellular signaling pathways that are induced during liver fibrosis. The paper then examines the effects of these signaling pathways on the major cell types in the liver. This will provide insights into the molecular pathophysiology of liver fibrosis and should identify therapeutic targets.

\section{Introduction}

Fibrosis is the outcome of many chronic liver diseases [1], including hepatitis B virus (HBV), hepatitis C virus (HCV), alcoholic liver disease, and nonalcoholic steatohepatitis (NASH), liver intoxication (drug or nutritionally related) [1]. It is manifested by massive accumulation of the extracellular matrix (ECM) and scar formation. Several injurytriggering events play a critical role in the pathogenesis of liver fibrosis. Chronic liver injury damages the endothelial barrier and induces apoptosis of hepatocytes. Apoptotic bodies and necrotic cells release chemokines that recruit inflammatory cells to the injured liver and release fibrogenic and inflammatory cytokines (TGF- $\beta 1$, IL-6, IL- $1 \beta$, and TNF- $\alpha$ ) that activate macrophages and hepatic stellate cells [2]. BM-derived and liver resident macrophages (Kupffer cells) are believed to be the major source of TGF- $\beta 1$ in fibrotic liver $[1,3]$. TGF- $\beta 1$ is critical for the activation of fibrogenic myofibroblasts, which in response to injury upregulate $\alpha$-smooth muscle actin ( $\alpha$-SMA) and secrete extracellular matrix proteins, mostly collagen Type I (Col), I, and III $[3,4]$. Hepatic stellate cells (HSCs) contribute $>80 \%$ of the myofibroblasts in the fibrotic liver in response to an hepatotoxic injury [5]. HSCs express unique markers such as Desmin and glial fibrillar acidic protein (GFAP), which distinguish them from other cells in the liver [1]. Under physiological conditions, HSCs store Vitamin A and retain a quiescent phenotype (qHSCs), but following TGF$\beta 1$ stimulation, PDGF, or matrix stiffness, or other fibrogenic stimuli they rapidly activate into type I collagen, $\alpha$-smooth muscle actin expressing myofibroblasts (aHSCs) $[1,4,6]$. In addition to HSCs, cholestatic liver injury causes activation of portal fibroblasts, which differentiate into myofibroblasts and contribute to scar formation $[7,8]$. Cholestatic injury also triggers cholangiocyte activation, and proliferation of the bile ducts (ductular reaction) [1]

\section{Overview of the Signaling Pathways Critically Involved in Pathogenesis of Liver Fibrosis}

2.1. TGF- $\beta$-Smad2/3. Signaling by the cytokine transforming growth factor- $\beta 1$ (TGF- $\beta 1$ ) plays a pivotal role in growth and differentiation, maintenance of liver homeostasis, terminal differentiation of hepatocytes and other epithelial cells, and cytokine-mediated mitogenic signaling $[1,9,10]$. The TGF- $\beta$ superfamily is composed of many multifunctional cytokines, including TGF- $\beta$ s 1,2 , and 3 , activin, and bone morphogenic proteins (BMPs) $[11,12]$. Under physiological conditions TGF- $\beta 1$ regulates tissues remodeling and apoptosis to maintain cellular homeostasis $[13,14]$. Under pathological conditions, TGF- $\beta 1$ is the strongest known inducer of fibrosis, being a direct regulator of fibrillar 
collagens, TIMP1, plasminogen activator inhibitor 1 (PAI1), p300 [15]. In response to injury, TGF- $\beta 1$ orchestrates a cross talk between parenchymal, inflammatory, and myofibroblast cells. Although many cells in the liver may produce TGF$\beta 1$, Kupffer cells and recruited macrophages are the major source of TGF- $\beta 1$ in the fibrotic liver. TGF- $\beta 1$ is critical for activation of HSCs into myofibroblasts [1]. aHSCs, and to lesser extend sinusoidal endothelial cells (ECs), also contribute to TGF- $\beta 1$ production [1].

To mediate its function, TGF- $\beta 1$ undergoes several important posttranslational modifications. TGF- $\beta 1$ is synthesized as a nonactive proform, cleaved intracellularly by the endopeptidase furin to generate mature form, but remains biologically inactive due to its association with a complex of two proteins: latency-associated peptide (LAP) and latent TGF- $\beta$-binding protein (LTBP). This large TGF$\beta 1$-associated complex is then secreted into the ECM, where it is crosslinked by tissue transglutaminase and stored as a reservoir without any effect on the surrounding tissue [16]. Inactive TGF- $\beta 1$ interacts with fibronectin. Briefly, two variations of FN exist: plasma $\mathrm{FN}(\mathrm{pFN})$, a dimeric and soluble form secreted by hepatocytes directly into the circulation; cellular FN (cFN), found in the ECM of tissues in a multimeric form containing alternatively spliced variants of extra domains EDA and EDB [17]. EDA cFN secreted by the cells or already present in the ECM activates latent TGF $\beta$ [17]. Mature TGF- $\beta 1$ is released from LAP/LTBP, the latency maintaining protein complex, by activation of thrombospondin 1 (TSP-1) $[18,19], \alpha \mathrm{v} \beta 6$ and $\alpha \mathrm{v} \beta 8$ integrins (heterodimeric matrix receptor expressed by epithelial cells, some dendritic cells, and macrophages), or acidification $[16,18,20-25]$. Alternatively, TGF- $\beta 1$ can be activated by several proteases such as plasmin or matrix metalloproteinases MMP-2 and 9, which directly induce degradation of the LAP/LTBP complex [26]. Neutrophil elastase, a serine protease released by neutrophil degranulation, has also been implicated in activation of latent TGF- $\beta 1$ $[24,25,27]$.

TGF- $\beta$ mediates its biological function via signaling through the downstream molecules Smads (Figure 1). The Smad family of proteins contain a conserved Mad-homology (MH) 1 domain, an intermediate linker, and a $\mathrm{MH} 2$ domain [28]. There are three classes of Smads: (1) receptor-regulated Smads (R-Smads), which include Smad1, 2, 3, 5, and 8; (2) common-mediator (co-Smad) Smad4; (3) antagonistic or inhibitory Smads, Smad6 and $7[10,29]$. Smads regulate the signals from the receptors for TGF- $\beta$ superfamily members to the nucleus. Catalytically active TGF- $\beta$ type I receptor $(\mathrm{T} \beta \mathrm{RI})$ and activin type I receptor (ActRI) phosphorylate serine residues of receptor-activated Smad2 and Smad3 [30]. Smad proteins have intermediate linker regions between conserved Mad homology (MH) 1 and MH2 domains. TGF$\beta$ Type I receptors differentially phosphorylate Smad 2 and Smad3 to create C-terminally (C), linker (L), or dually (L/C) phosphorylated (p) isoforms. Although $\mathrm{COOH}$-tail phosphorylation by T $\beta$ RI is a key event in R-Smad activation, additional phosphorylation can positively and negatively regulate R-Smads pathway. Thus, the linker domain undergoes

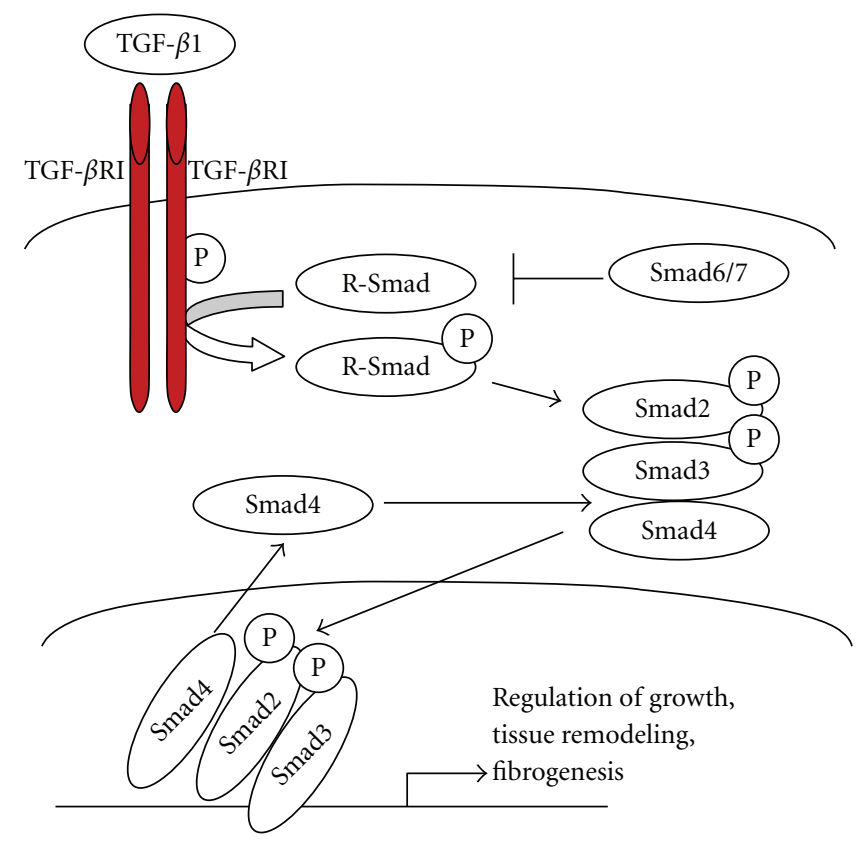

FIgUre 1: TGF- $\beta 1$ signaling. At the cell surface, TGF- $\beta 1$ binds a complex of transmembrane receptor serine/threonine kinases types I and II (TGF- $\beta$ RI and TGF- $\beta$ RII) and induces transphosphorylation of the the type I receptor by the type II receptor kinases. The activated type I receptor phosphorylates Smad2 and Smad3, which then form a complex with a common Smad4. Activated Smad complexes translocate to the nucleus and function as transcription factors. Activation of R-Smads by type I receptor kinases is inhibited by Smad6 or Smad7. R-Smads and Smad4 shuttle between nucleus and cytoplasm.

regulatory phosphorylation by JNK and cyclin-dependent kinase (CDK) pathways [31].

Activated Smad2/3 complex forms hetero-oligomers with Smad4. In association with Smad4, the Smad2/3 complex is translocated to the nucleus, where it initiates transcription of TGF- $\beta 1$ target genes. This pathway is regulated by several autoinhibitory feedback loops, for example, Smad7, Ski, SnoN, and Bambi are negative regulators of TGF- $\beta 1$ signaling $[22,32]$.

Studies of genetically altered mice have demonstrated the importance of TGF- $\beta 1$ signaling pathway for development of fibrosis. Overexpression of TGF- $\beta 1$ in transgenic mice results in fibrosis of multiple organs [1], and TGF- $\beta 1^{-/-}$ mice strongly attenuate the development of liver fibrosis $[1,33,34]$. Consistently, Smad3 ${ }^{-/-}$mice, which lack the Smad 3 signaling molecule downstream of TGF- $\beta 1$, are much less susceptible to liver fibrosis than wild type mice $[24,25$, 35]. The role of Smad2 in fibrosis is less well characterized due to the lethal phenotype of Smad2 $2^{-1-}$ mice, but in comparison with Smad3, seems to regulate a distinct set of target genes [36]. TGF- $\beta$ signaling can also be mediated by noncanonical, "non-Smad," signaling pathways, triggered by phosphorylation of the Smad linker region [37] or by recruitment of other proteins, such as MAPK, PP2A $/ \mathrm{p} 70^{\mathrm{S} 6 \mathrm{~K}}$, RhoA, and TAK1/MEKK1 to the activated TGF $\beta$ receptor complex without a direct effect on Smad activation $[37,38]$. 
2.2. $N F \kappa B$. Nuclear factor $\kappa \mathrm{B}(\mathrm{NF} \kappa \mathrm{B})$ is a key transcription factor involved in a broad range of biological processes, including immune responses, cell survival, stress responses, and maturation of various cell types [39]. $\mathrm{NF} \kappa \mathrm{B}$ is composed of hetero- or homodimers formed by the Rel protein family (p65, p50, p52, c-Rel, and RelB), all containing the Rel homology domain (RHD) [40, 41]. The canonical $\mathrm{p} 65: \mathrm{p} 50$ heterodimer is the most abundant dimer in $\mathrm{NF} \kappa \mathrm{B}$ signaling pathway $[40,41]$. Generation of each monomer is transcriptionally regulated, but p50 and p52 are also regulated by processing of precursor proteins $\mathrm{p} 105$ and p100, respectively [39].

The functional activity of $\mathrm{NF} \kappa \mathrm{B}$ is determined by its natural stoichiometric inhibitors I $\kappa$ Bs $[40,41]$. The classical inhibitor proteins in the $\mathrm{NF} \kappa \mathrm{B}$ signaling system consist of the single polypeptide $\mathrm{I} \kappa \mathrm{B} s \mathrm{I} / \kappa \mathrm{B} \alpha, \mathrm{I} \kappa \mathrm{B} \beta$, and $\mathrm{I} \kappa \mathrm{B} \varepsilon$, characterized by their ankyrin repeat domain (ARD) [40, 41]. In resting cells, I $\kappa \mathrm{B}$ binds the $\mathrm{NF} \kappa \mathrm{B}$ dimer and prevents its nuclear translocation and DNA binding. $\mathrm{I} \kappa \mathrm{B} \alpha$ is the most common inhibitor, which directly interacts with $\mathrm{NF} \kappa \mathrm{B}$ to form inactive complexes residing in the cytoplasm. Following cytokine stimulation, activation of the I $\kappa \mathrm{B}$ kinase (IKK) in turn induces phosphorylation, ubiquitination and subsequent $\mathrm{I} \kappa \mathrm{B} \alpha$ degradation, releasing active $\mathrm{NF} \kappa \mathrm{B}$ [42] (Figure 2). Released $\mathrm{NF} \kappa \mathrm{B}$ translocates to the nucleus where it initiates transcription of $\mathrm{NF} \kappa \mathrm{B}$ target genes via direct binding to $\mathrm{NF} \kappa \mathrm{B}$-specific DNA motifs (GGGRNNYYCC, where $\mathrm{R}$ is purine, $\mathrm{Y}$ is pyrimidine, and $\mathrm{N}$ is any base). Interestingly, $\mathrm{I} \kappa \mathrm{B} \alpha$ itself is one of the $\mathrm{NF} \kappa \mathrm{B}$ target genes $[40,41]$. Synthesis of other members of the I $\kappa \mathrm{B}$ family is also dependent on $\mathrm{NF} \kappa \mathrm{B}$ activity via negative feedback. Subsequent studies have suggested that there are two pathways of $N F \kappa B$ activation [39]. The canonical NF $\kappa B$ pathway is defined as being mediated by a NEMO-dependent kinase IKK (IKK $\gamma$ ) activation; while the noncanonical pathway is NEMO-independent kinase complex involving IKK $\alpha$ (IKK1) and the $\mathrm{NF} \kappa \mathrm{B}$-inducing kinase (NIK) [43]. In the canonical pathway, preexisting, latent $\mathrm{NF} \kappa \mathrm{B}$ dimers are released from classical I $\kappa$ Bs. In the noncanonical pathway, new synthesis of p100 and RelB allows for generation of RelB : p52 which is insensitive to $\mathrm{I} \kappa \mathrm{B}$ control and thus translocates to the nucleus [39].

The importance of these findings has been confirmed using knockout mice. Thus, deletion of NEMO (IKK $\gamma$ ) resulted in embryonic lethality in mice caused by a massive apoptosis in the fetal liver [44]. Similar to that, the IKK $\beta$ (IKK2) knockout [45] and the RelA knockout [46] have a lethal phenotype, suggesting that all these proteins are involved in one signaling axis of NEMO-IKK $\beta$-RelA. IKK $\alpha$ may compensate for the loss of IKK $\beta$ (IKK2) [47]. Moreover, studies of genetically deficient mice demonstrate an essential role of the noncanonical $\mathrm{NF} \kappa \mathrm{B}$ pathway in various biological processes, including regulation of developmental signals. Thus, mice lacking $\mathrm{RelB}^{-/-}, \mathrm{N} f \kappa B 2^{-/-}$, and $N I K^{-/-}$have defective development of lymph nodes and Peyer's Patch $[39,48,49]$.

2.3. LPS-TLR4. Liver fibrogenesis is associated with increased intestinal permeability [1]. Bacterial products, including lipopolysaccharide (LPS, cell walls of gram-negative bacteria), signal via Toll-like receptor pathways. Toll-like receptors (TLRs) are innate immune signal receptors which recognize pathogen-associated molecular patterns (PAMP) such as LPS, peptidoglycan, and bacterial derived unmethylated CpG-DNA. In addition, endogenous ligands (alarmins) can bind TLR4 in the presence of CD14 and LPS binding protein (LBP) and transduce similar signals [50]. Thus, endogenous ligand HMGB-1, hyaluronan, and products of dying cells have been shown to trigger TLR signaling. LPS binds to TLR4 with its coreceptors MD-2 and CD14 and transmits its signal through adaptor proteins MyD88, TIRAP, TRIF, and TRAM to activate the kinases, IRAK1, IRAK4, TAK1, JNK, and IKK (Figure 3). These intracellular kinases lead to the activation of the transcription factors $\mathrm{NF} \kappa \mathrm{B}, \mathrm{AP}-1$, and interferon regulatory factors (IRFs), resulting in the induction of potent innate immune responses [3, 51]. Upon activation of TLRs, cells produce proinflammatory cytokines, such as TNF- $\alpha$, IL-6, IL-1, MCP-1, and RANTES [50].

Using TLR4-chimeric mice and in vivo lipopolysaccharide (LPS) challenge, Seki et al. have shown that quiescent hepatic stellate cells (HSCs), the main precursors for myofibroblasts in the liver, are the predominant target through which TLR4 ligands promote fibrogenesis. In quiescent HSCs, TLR4 activation not only upregulates chemokine secretion and induces chemotaxis of Kupffer cells, but also downregulates the transforming growth factor TGF- $\beta 1$ pseudoreceptor Bambi to sensitize HSCs to TGF-beta-induced signals and allow for unrestricted activation by Kupffer cells [3].

TLRs are critical in liver fibrosis $[3,52]$. Patients with hepatic cirrhosis have elevated portal vein levels of LPS. Portal hypertension can damage the intestinal mucosa compromising its barrier function and trigger bacterial translocation. The liver has a unique vascular system within the gastrointestinal tract, as the majority of the liver's blood supply comes from the intestine through the portal vein. When the intestinal barrier function is disrupted, an increase in intestinal permeability leads to the translocation of intestinederived bacterial products such as lipopolysaccharide (LPS) and unmethylated $\mathrm{CpG}$ containing DNA to the liver via the portal vein. These gut-derived bacterial products stimulate innate immune receptors, namely Toll-like receptors (TLRs), in the liver. TLRs are expressed on Kupffer cells, endothelial cells, dendritic cells, biliary epithelial cells, hepatic stellate cells, and hepatocytes. TLRs activate these cells to contribute to acute and chronic liver diseases [53-56]. Therefore, LPS derived from the intestinal microflora is a strong candidate for the TLR4 ligand in hepatic fibrosis [57]. Consistently, gut sterilization with antibiotics attenuates liver fibrosis, and pathogen free animals are resistant to liver fibrosis [3]. Mice with deficiencies in components of TLR4 signaling pathway, CD14, LPS binding protein (LBP), or TLR4 have impaired TLR signaling and are less susceptible to liver fibrosis [58].

In addition, fragments of fibronectin have been implicated in physiological and pathological processes, especially tissue remodeling associated with inflammation [17]. Cellular fibronectin containing an alternatively spliced exon 


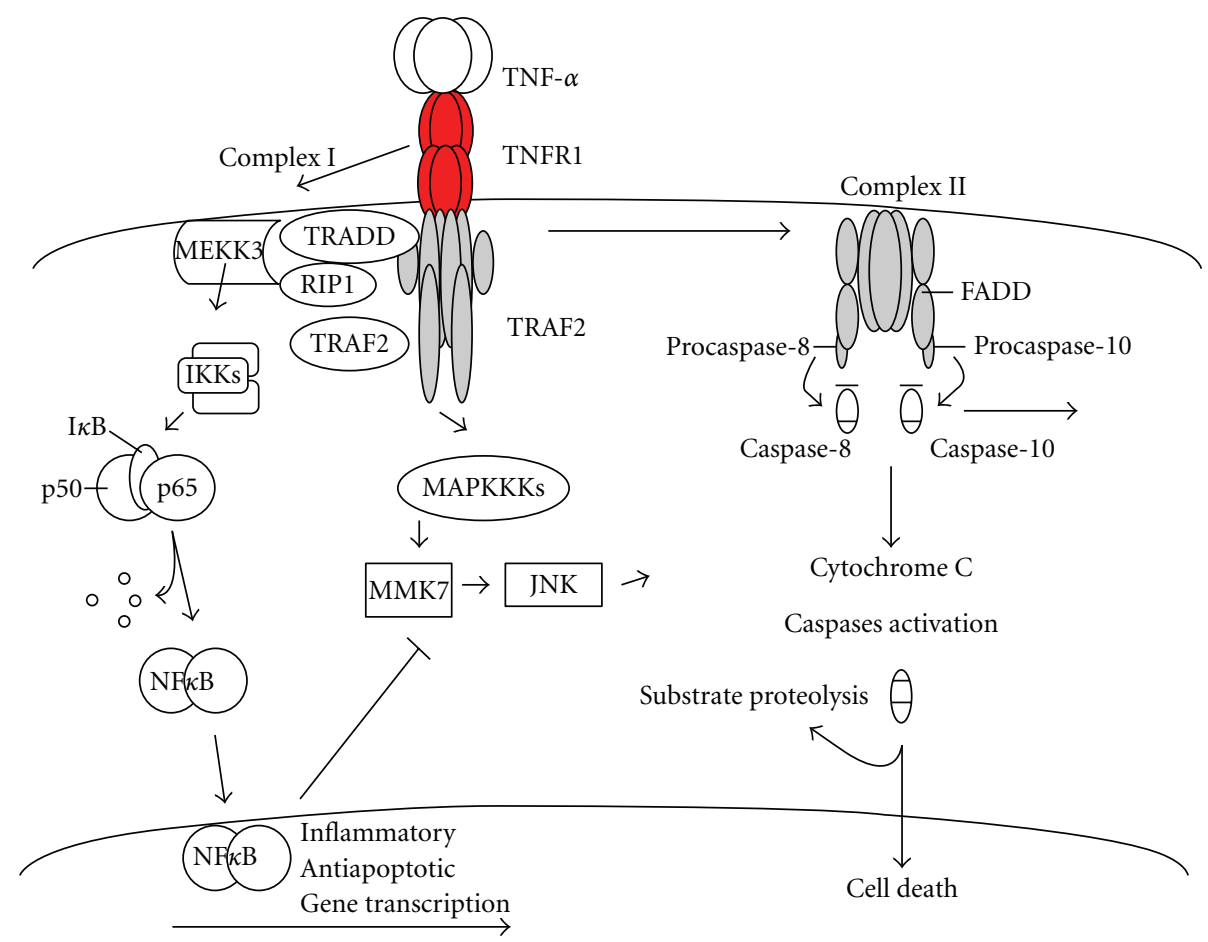

FIGURE 2: Formation of the NF $\kappa$ B-stimulating TNFR1 signaling complex. The classical NF $\kappa$ B pathway is activated by a broad range of stimuli, including TNF- $\alpha$. Binding of TNF- $\alpha$ to TNFR1 triggers recruitment of the death domain-containing proteins RIP1 and TRADD. Next, complex TRAF2-cIAP1/2 is recruited to TNFR1-bound TRADD. Recruitment of IKK2 subunit to TRADD-bound TRAF2 stimulates kinase activity of the IKK complex, following by proteolytic degradation of I $\kappa$ B proteins. p65/p50 complex (NF $\kappa$ B) is translocated to the nucleus to activate transcription of target genes. Alternative NF $\kappa \mathrm{B}$ pathway (not shown) is activated by a limited subgroup of TNF ligands and involves activation of NIK-mediated stimulation of IKK1 and conversion of p100-containing NF $\kappa$ B complexes into p52-containing NF $\kappa B$ complexes by proteolytic processing of p100 to p52. In addition, in TNF-mediated apoptosis, receptor aggregation results in recruitment of the adaptor protein Fas-associated death domain (FADD/MORT1) and caspase-8. Caspase- 8 becomes activated and initiates apoptosis by direct cleavage of downstream effector caspases. The mitochondrial pathway is initiated by the release of apoptogenic factors such as cytochrome $c$, or Smac from mitochondria into the cytosol, which trigger caspase-3 activation through the formation of the cytochrome c/Apaf-1/caspase-9-containing apoptosome complex.

encoding type III repeat extra domain A (EDA) is produced in response to tissue injury $[59,60]$. EDA-containing fibronectin fragments produce cellular responses similar to those provoked by bacterial lipopolysaccharide (LPS). EDAcontaining fibronectin binds to and activates TLR4 [60], inducing nuclear translocation of nuclear factor NF $\kappa B$ [61].

2.4. Stat3 Signaling. The Janus kinase-signal transducers and activators of transcription (Jak-Stat) signaling pathways are activated in the liver by more than 20 cytokines and growth factors and play a critical role in a variety of cellular functions, such as antiviral defense, acute phase response, hepatic injury, repair, inflammation, transformation, and hepatitis $[62,63]$. Stat 3 was originally identified as an acutephase response factor, activated by IL- 6 and other cytokines [64], but has been implicated in cellular transformation and carcinogenesis [65]. Stat3 is expressed in most tissues and early during postimplantation. Consistent with this, disruption of the Stat 3 gene leads to an early embryonic lethal phenotype [66]. Tissue specific Stat3 knockouts have been generated using floxed alleles. Stat 3 deficient $\mathrm{T}$ cells exhibit a lower proliferative response to IL-6, which suppresses apoptosis in these cells [67]. Stat3 deleted macrophages (and neutrophils) have aberrant IL-10 signaling and immune regulation [68]. Stat3 null mammary gland epithelial cells exhibit a delay in programmed cell death that occurs during cyclical gland involution [69]. Mice with Stat3deficient hepatocytes exhibit defects in their ability to induce acute phase response genes (e.g., serum amyloid protein (SAP), fibrinogen (FB), haptoglobin (HP), serum amyloid A protein (SAA), and hemopexin (Hpx) in response to IL6 [70]. In addition, Stat3 signaling in hepatocytes provides antiapoptotic cytoprotection [71]. Deletion of this pathway abolishes the induction of the acute-phase response, leading to more severe cholestasis and an enhanced inflammatory response with increased TNF- $\alpha$ expression and subsequent cytotoxicity [71].

Cytokine signaling plays a pivotal role in the pathogenesis of liver fibrosis, which was assumed to be linked to deregulation of Th1/Th2 homeostasis towards Th2 responses [72]. However, expression of profibrogenic cytokines does not always correlate with the Th1/Th2 classification. Thus, despite driving a Th2 response, IL-6 and IL-10 have antifibrogenic effects (Figure 4). Hepatic fibrosis was increased 


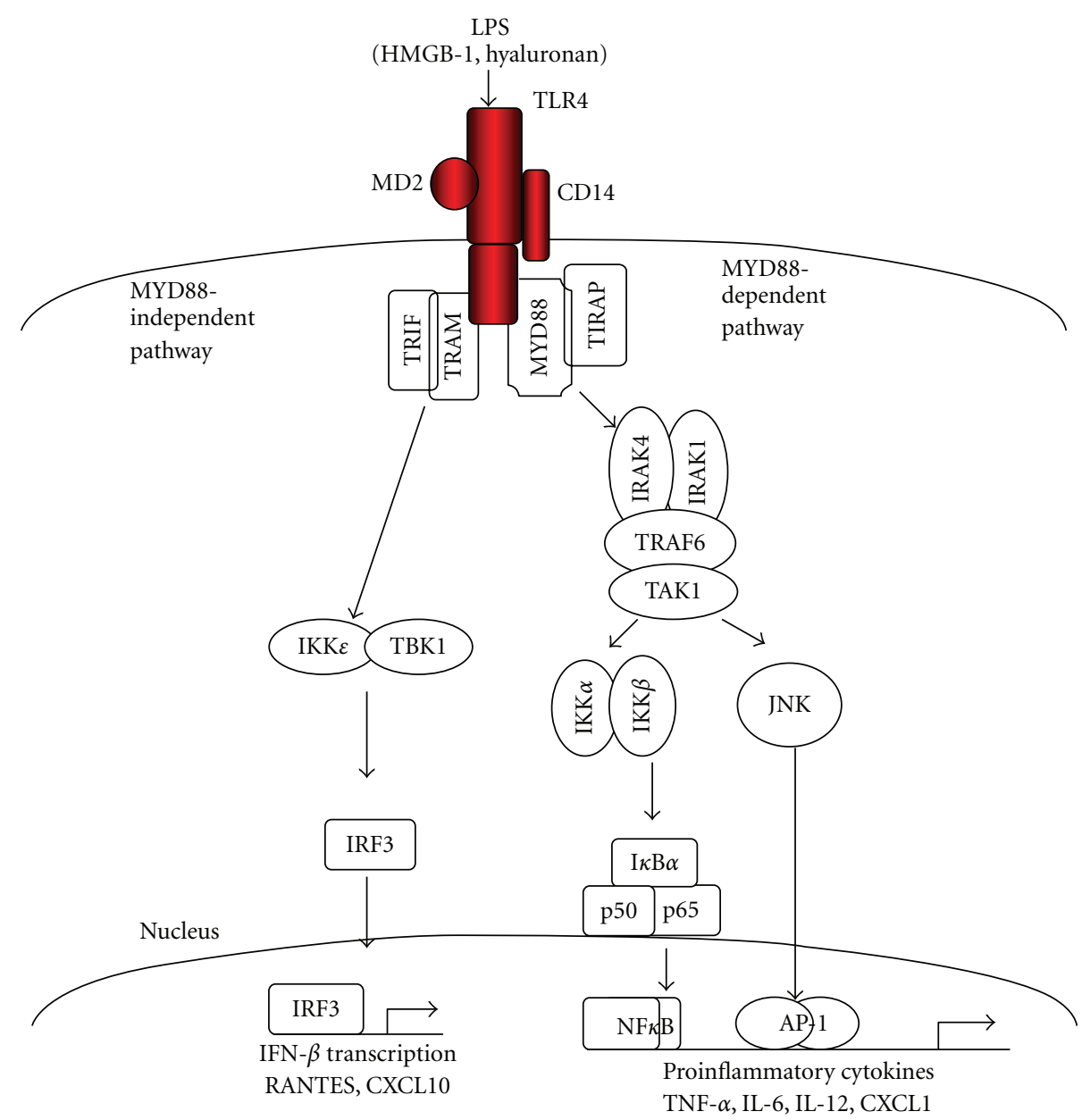

FIGURE 3: Schematic overview of TLR4 signaling pathways. LPS and other ligands bind TLR4, which transmit the signals through MyD88 to the activation of NF $\kappa$ B and p38/c-Jun N-terminal kinase (JNK). TIRAP bridges TLR4 with MyD88. TRAF is utilized by TLR4/TRAM to activate TBK1/inhibitor of $\mathrm{NF} \kappa \mathrm{B}$ kinase (IKK) $\epsilon$ leading to IRF-3 activation followed by IFN- $\beta$ production.

in $\mathrm{IL}-6^{-/-}$mice and in IL-10 $10^{-/-}$mice due to the loss of hepatocyte protection [73-75]. IL-22, a member of the IL10 family of cytokines, also signals via the Jak2-Stat3 pathway and mediates hepatocyte survival during liver injury [76, 77].

\section{Signaling Cascades Activated in Different Cell Types during Liver Fibrogenesis}

3.1. Hepatocytes. Hepatocytes contribute to $80 \%$ of liver mass. Hepatocytes play a critical role in metabolism and detoxification for the organism [78] and are the major storage of glycogen. In the normal adult liver, mature hepatocytes exhibit a quiescent phenotype, stay in the G0 phase of the cell cycle, and show minimal turnover. However, upon hepatocyte loss (such as toxic liver injury, infection, or surgical resection), these mature hepatocytes proliferate, while maintaining their metabolic function. Hepatocyte function is heterogeneous, in part due to their location within the acinus [79, 80]. For example, while pericentral hepatocytes (adjacent to the central vein) express glutamine synthase, ornithine aminotransferase, and thyroid hormone receptor $\beta 1$, periportal hepatocytes (adjacent to the portal triad) upregulate HNF- $\alpha$ and convert ammonia to urea [81, $82]$.

3.1.1. TGF- $\beta$-Smad2/3 Signaling. TGF- $\beta$ signaling in hepatocytes is implicated in negative regulation of the growth response. TGF- $\beta$ type I receptor (T $\beta \mathrm{RI}$ ) differentially phosphorylates $\mathrm{COOH}$-tail serine residues of receptor-activated Smad (R-Smad, which include Smad2 and Smad3 to create three phosphorylated forms (phosphoisoforms) [30]: COOH-terminally phosphorylated R-Smad (pSmad2C and pSmad3C), linker-phosphorylated R-Smad (pSmad2L and pSmad3L), and dually phosphorylated R-Smad (pSmad2L/C and $\mathrm{pSmad} 3 \mathrm{~L} / \mathrm{C})[9,83,84]$. While $\mathrm{pSmad} 2 \mathrm{~L}$ resides in the cytoplasm, the other phosphoisoforms are localized to cell nuclei [31]. In homeostasis, TGF- $\beta$-mediated pSmad3C signaling in hepatocytes opposes proliferative responses induced by mitogenic signals, causing arrest of cell cycle progression in the G1 phase by downregulation of c-Myc and induction of $\mathrm{p} 21^{\mathrm{WAF} 1}[28,85]$. Acute liver injury induces 


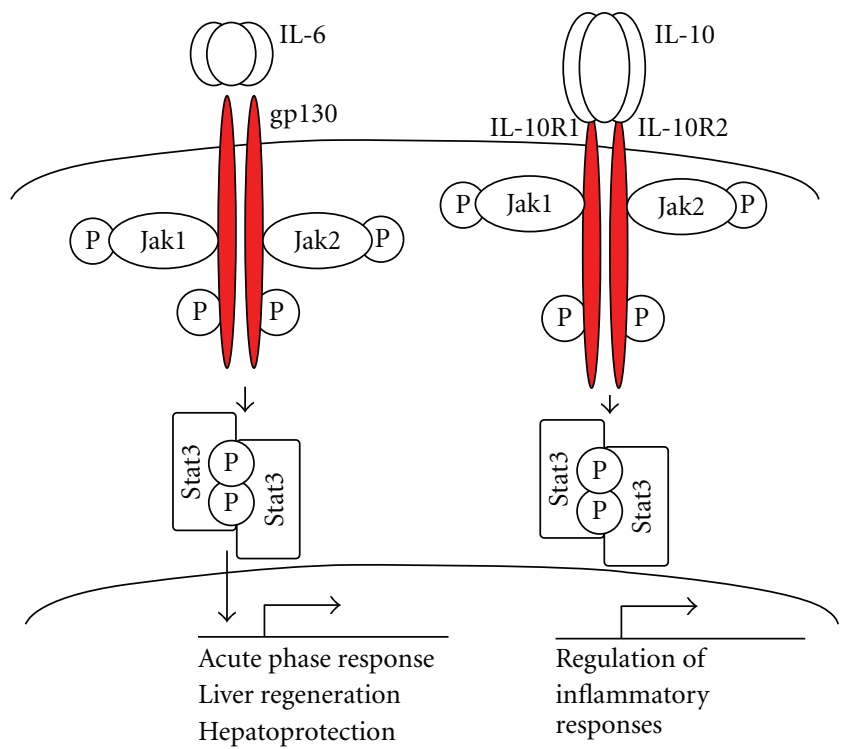

FIGURE 4: Schematic overview of Jak/Stat signaling pathways. IL-6 signals through gp130, which is a common receptor chain for IL6 and the IL-6 receptor. Hepatocytes express high level of gp130 and IL-6. IL-6 binding to its corresponding receptors leads to the dimerization of gp130, followed by dimerization of gp130associated Jak 1 and Jak2, and phosphorylation of Jaks and gp130. This receptor-kinase complex then recruits and phosphorylates cytoplasmic protein Stat3. Phosphorylated Stat3 forms dimers, translocates into the nuclei, and induces gene transcription. Binding of IL-10 to its corresponding receptors IL-10R1 and IL-10R2 leads to Jak and then Stat3 phosphorylation, which then functions as a transcription factor.

secretion of proinflammatory cytokines, as well as TGF- $\beta$ and activin A [9]. In turn, the loss of liver parenchyma triggers proliferation of resting hepatocytes. Even though TGF- $\beta$ and activin concentrations are elevated, mitogenic proinflammatory cytokines regulate liver regeneration by shifting from cytostatic pSmad3C signaling to mitogenic pSmad3L signaling. This phenomenon allows hepatocytes to acquire "temporary resistance" to TGF- $\beta$ (and activin A) and proliferate during liver regeneration [86, 87]. Inflammatory cytokine-induced $\mathrm{pSmad} 3 \mathrm{~L}$ stimulates c-Myc transcription $[88,89]$, which increases the proliferation of regeneration of hepatocytes and suppresses the cytostatic action of the $\mathrm{pSmad} 3 \mathrm{C} / \mathrm{p} 21^{\mathrm{WAF} 1}$ pathway [9].

TGF- $\beta$-Smad2/3 signaling in hepatocytes has also been implicated in epithelia-to-mesenchymal transition (EMT), a process in which fully differentiated epithelial cells undergo phenotypic transition to fully differentiated mesenchymal cells (fibroblasts or myofibroblasts) [90]. During EMT, epithelial cells detach from the epithelial layer, lose their polarity, downregulate epithelial markers (e.g., hepatocyte marker albumin, cytokeratins, cadherins) and tight junction proteins (zonula occludens-1, ZO-1), increase their motility, and obtain a myofibroblast phenotype [91], with upregulated expression of $\alpha$-smooth muscle actin (SMA) and vimentin in EMT-originated myofibroblasts. Epithelial cells transitioning into myofibroblasts are also reported to express fibroblast specific protein-1 (FSP1, S100A4), which is used as a marker of EMT in fibrogenesis and cancer [91-94]. Hepatocytes have been implicated in EMT in response to liver injury [95], suggesting that mature hepatic epithelial cells can contribute to fibrogenic myofibroblasts and collagen production in response to injury. EMT has been originally described during embryonic development [91] and plays a critical role in TGF- $\beta$-induced organogenesis. However, the role of EMT in fibrogenic disease has been recently questioned [96]. Studies based on the genetic labeling of hepatocytes, using AlbuminCre mice, have demonstrated that hepatocytes are capable of differentiating into myofibroblasts in vitro, but not in vivo [97]. Moreover, FSP1 is not a robust marker for EMT, since its expression is not restricted to EMT-transitioning cells, but is expressed by myelomonocyic lineage cells [98-100].

TGF- $\beta$ induces expression of growth factors and cytokines by hepatocytes. Moreover, hepatocytes serve as a significant source of BMP-7, a natural inhibitor of the TGF$\beta 1$-signaling pathway belonging to the TGF- $\beta$ superfamily. Administration of BMP-7 in pharmacological doses attenuates the development of kidney fibrosis and liver fibrosis [101-103]. Hepatocyte-specific deletion of Smad7 results in spontaneous liver dysfunction and aggravation of alcoholinduced liver injury [104].

3.1.2. LPS-TLR4 Signaling. Consistent with their filtering/detoxification function, hepatocytes express TLRs which are constitutively engaged by bacterial products in the liver [105]. Primary cultured hepatocytes express mRNA for all TLRs, but are capable of responding only to TLR 2 and TLR4 ligands in vitro. However, TLR2 and TLR4 signaling in hepatocytes is fairly weak in vivo [106-108]. Under inflammatory conditions, hepatocytes upregulate TLR2 and become more sensible to TLR2-mediated signals. At the same time, TLR4 expression in hepatocytes is not strongly upregulated [109]. Although hepatocytes express TLR4 and are capable of transmitting TLR4 signals in vitro, the contribution of TLR4 signaling in hepatocytes is limited. Meanwhile, the TLR/MyD88-mediated pathway is required for the initiation of liver regeneration after partial hepatectomy $(\mathrm{PH})[108$, 110].

3.1.3. TNF- $\alpha-N F \kappa B$. Chronic injury causes an imbalance between the production of protective and damaging cytokines, resulting in the activation of apoptotic signals in hepatocytes. TNF- $\alpha$ and related cytokines play a key role in mediating hepatocyte homeostasis by regulating both antiand proapoptotic pathways. TNF- $\alpha$ signals through TNF-R1 and TNF-R2, of which TNF-R1 plays a critical role in TNF$\alpha$-mediated activity in the liver. The proapoptotic effects of TNF- $\alpha$ result from a cascade of caspase activation. This pathway is initiated by TNF- $\alpha$-induced TNF-R1 receptor crosslinking, recruitment of TRADD and FADD (adaptor protein TNF receptor TRADD and Fas-associated death domain FADD) and cleavage of caspase 8 , which activates the downstream proapoptotic caspases (caspases 3, 6, 7). In turn, the activation of TNF- $\alpha$-dependent prosurvival signals is mediated by $\mathrm{NF} \kappa \mathrm{B}$ activation and involves transcriptional 
expression of suppressors of apoptosis, including Bcl-2, Bcl$\mathrm{xL}$, and Bfl-1 [111]. However, TNF $\alpha$ also activates NFא B, rendering hepatocytes resistant to apoptosis unless also treated with cycloheximide, actinomycin D or the superrepressor of $\mathrm{I} \kappa \mathrm{B}[112,113]$.

3.1.4. IL-6-Stat3 Signaling. In hepatocytes, IL-6 plays a crucial role in liver regeneration and transmits its mitotic signals mainly through Stat3. IL-6 stimulates hepatocytes to produce acute-phase response proteins, including serum amyloid A, complement C3 and C-reactive protein. In IL-6deficient mice, Stat 3 activation is dramatically suppressed in hepatocytes [80]. Although Stat3 signaling can be induced by other cytokines, such as G-CSF [114] and leptin [115], current data suggests that Stat3 in hepatocytes is almost exclusively activated by IL-6. Thus, hepatocyte regeneration in response to partial hepatectomy triggers activation of the IL-6/Stat3 signaling pathway, composed of IL-6 receptor, gp130, receptor-associated Janus kinase (Jak), and Stat3. The IL-6 receptor forms a complex with two molecules of gp130 [62].

Stat3 promotes liver regeneration by promoting cell cycle progression from G1 to $S$ phase [116]. Stat3 regulates the expression of cyclin D1 [117], which is required for hepatocyte proliferation [118]. As expected, hepatocytespecific Stat3-deficient mice exhibit impaired DNA synthesis and mitotic activity of hepatocytes after partial hepatectomy.

Other target genes of Stat3 include antiapoptotic genes FLIP, $B c l-2$, and $B c l-x L[118,119]$. Therefore, it is believed that Stat3 prevents liver damage by its antiapoptotic and promitogenic effects [78]. Deletion of the gp130/Stat3 pathway in hepatocytes leads to increased hepatotoxicity and accelerates liver injury and inflammation [71]. This effect is likely mediated via the Stat 3 induction of EGFR and IGF-1 signaling pathways [120]. Interestingly, Stat3 also possesses antioxidative capacity. Hypoxia and reperfusion injures hepatocytes via the generation of reactive oxygen species (ROS) and activation of redox-sensitive caspases such as caspase-3/-9. Stat3 upregulates Ref-1 [121] and MnSOD [122], which protects hepatocytes from ROS-mediated apoptotic cell death [118]. Thus, activation of Stat3 in hepatocytes has hepatoprotective and anti-fibrotic effects [123].

3.2. Kupffer Cells. Kupffer cells are liver-resident macrophages, which are long lived and radiation resistant. They express myeloid markers such as F4/80, CD68, CD11b, CCR2, and CX3CR1 [51, 124, 125]. However, there are currently no specific markers distinguishing Kupffer cells from recruited BM derived macrophages. It is believed that both of these populations actively participate in development of liver fibrosis by secretion of TGF- $\beta 1$, IL- 6 and other profibrogenic cytokines.

3.2.1. TLR Signaling. Kupffer cells are well established targets for the TLR4 ligand LPS and produce inflammatory and fibrogenic cytokines, which may activate HSCs [126]. However, TLR4 signaling in Kupffer cells is not critical for the pathogenesis of experimental liver fibrosis. Deletion of TLR4 signaling in BM-derived inflammatory cells and Kupffer cells was achieved in BM-chimeric mice, pretreated with clodronate (to reconstitute long-lived Kupffer cells). Interestingly, only a modest inhibition of liver fibrosis was observed in these mice in response to liver injury $[3,51]$. However, LPS, but not TGF- $\beta$, is a strong activator of Kupffer cells in vitro and in vivo. LPS-stimulated Kupffer cells secrete TNF- $\alpha$ and TGF- $\beta$. Furthermore, experimental alcoholic liver disease requires TLR4 on BM derived macrophage and Kupffer cells [51, 127]. Interestingly, only a modest inhibition of liver fibrosis was observed in these mice in response to liver injury. These results indicate that LPS-induced fibrosis does not need Kupffer cell-mediated activation of HSC.

3.2.2. IL-6-IL-10-Stat3 Signaling. IL-6 and IL-10 induce opposing effects on macrophages. IL-6 signals via gp130 and IL-6R and promotes inflammatory responses in Kupffer cells/macrophages. In turn, IL-10 secreted by Th1 and $\mathrm{T}$ cells stimulate IL-10R1 and IL-10R2 on Kupffer cells/macrophages, causing their prolonged activation. Activation of IL-10-Stat3 signaling inhibits inflammatory responses. Stat 3 upregulates expression of the suppressor of cytokine signaling 3 (SOCS3) [128], which binds to gp130, limiting IL-6-induced inflammatory responses [78]. Thus, while IL-6 triggers proinflammatory responses in macrophages, IL-10 mediates anti-inflammatory responses that are associated with decreased liver fibrosis $[78,128]$.

3.3. Endothelial Cells. Liver sinusoidal endothelial cells (LSECs) maintain the integrity of hepatic sinusoids and mediate barrier function, blood clearance, vascular tone, immunity, hepatocyte growth, and injury-induced angiogenesis [129-131]. LSECs differ from other ECs by the lack of basement membrane and together with hepatic stellate cells HSCs (residing in the space of Disse and acting as pericytes in the normal liver), form a fenestrated monolayer which regulates the blood supply to underlying hepatocytes [1]. Regulation of hepatic vascular tone is mediated by HSC contractility mediated by endothelin-1, angiotensin II, norepinephrine, prostaglandin $\mathrm{F} 2$, thromboxane $\mathrm{A} 2$, and thrombin $[1,132]$. Disruption of the integrity of the endothelium results in defenestration and capillarization of LSECs, and activation of an antifibrinolytic cascade to support coagulation and hemostasis [133]. In turn, LSECs secrete cytokines and soluble factors (such as monocyte chemoattractant protein 1 (MCP-1) and endothelin-1(ET-1)) that induce recruitment of inflammatory cells, contractility of HSCs, and platelet aggregation and degranulation [129]. In turn, as a part of a wound healing process, LSECs proliferate and migrate. In response to chronic injury, numerous mediators of angiogenesis, including angiopoietins, transforming growth factor (TGF- $\beta 1$ ), platelet-derived growth factor (PDGF), tumor necrosis factor-alpha (TNF- $\alpha$ ), interleukins, and members of the fibroblast growth factor family (FGF), are produced [134]. However, vascular endothelial growth factor (VEGF) remains the strongest inducer of angiogenesis [135]. 
Damage to the hepatic endothelium is further increased by portal hypertention and NO production, which accompany fibrogenic liver injury. NO production increases vasodilation and permeability of LSECs. Dysfunctional LSECs contribute to local production of NO production, further facilitating liver injury $[10,133]$.

\subsubsection{Angiotensin 1 and VEGF. VEGF is an important regu-} lator of angiogenesis and vascular tone. VEGF controls LSEC survival, proliferation, migration, and angiogenesis. VEGF binds to the receptor VEGFR2 and mediates its biological responses through reactive oxygen species (ROS) [136]. Another strong angiogenic factor, Angiopoietin 1 (Ang 1), regulates maturation and stability of blood vessels. Moreover, neovascularization induced during the development of livers fibrosis is mediated by Angiopoietin 1, expressed mostly by activated HSCs [137]. In turn, Ang 1 signals through endothelial receptor tyrosine kinase Tie2 and synergistically enhances VEGF's effects [138]. VEGF binds to its receptor and activates an Akt signaling cascade to increase vascular tone and the formation of collateral circulation $[139,140]$.

Furthermore, proliferation and migration of endothelial cells depends on pericyte coverage of vascular sprouts for vessel stabilization. This process is regulated by VEGF and platelet-derived growth factor (PDGF) through their cognate receptors [141]. VEGFR is expressed on endothelial cells, and PDGFR is expressed on HSCs and vascular smooth muscle cells (VSMCs). Moreover, it is believed that PDGF$\mathrm{R} \beta$ is exclusively expressed by HSCs in the liver and strongly upregulated in HSCs in response to fibrogenic liver injury [1]. PDGF induces neovascularization by priming VSMCs/pericytes to release pro-angiogenic mediators. VEGF acts as a negative regulator of neovascularisation. Specifically, while pericyte-derived PDGF mediates angiogenesis, VEGF ablates pericyte coverage of nascent vascular sprouts, leading to vessel destabilization. VEGF-mediated activation of VEGF-R2 suppresses PDGF-R $\beta$ signaling in HSCs/pericytes/VSMCs through the assembly of a previously undescribed receptor complex consisting of PDGF-R $\beta$ and VEGF-R2 [141]. Thus, VEGF ameliorates development of liver fibrosis and can serve as a novel target for anti-fibrotic therapy [142].

3.3.2. TGF- $\beta$-Signaling. TGF- $\beta$ signaling in endothelial cells plays a critical role in vascular development and maintenance of vascular homeostasis. Mice deficient for various TGF- $\beta$ signaling components have an embryonic lethal phenotype due to vascular defects, abnormal yolk sac vasculogenesis and/or angiogenesis $[143,144]$. TGF- $\beta$ is also essential for vascular integrity in the adults due to its role in regulation of anti-inflammatory characteristics of endothelial cells, growth and migration [145]. Similar to other cell types, TGF- $\beta$ signaling in endothelial cells results in activation of TGF- $\beta$ receptors with Ser/Thr kinase activity. The effect of TGF- $\beta$ on endothelial cells is dose-dependent. Low levels of TGF- $\beta$ promote angiogenesis, while higher doses inhibit angiogenesis [146]. TGF- $\beta$ regulates the activation of the endothelium via two opposing type I receptor/Smad pathways, activin receptor-like kinase (ALK)1 and ALK5 [145]. The classical TGF- $\beta$ type I receptor that activates Smad $2 / 3$ signaling is ALK5 (TGF $\beta$-RI). ALK2 (ActRI) is typically used by BMPs to activate Smads1/5/8. Use of ALK2 by TGF- $\beta$ is rather an exceptional nonhepatic event [147]. Typically the Smad2/3 pathway is activated by the type I receptors ALK4, 5 or 7 [28]. Furthermore, a coreceptor of TGF- $\beta$, endoglin (CD105), is upregulated on proliferating endothelial cells and facilitates effective TGF- $\beta$-ALK1 signaling [148, 149]. Another molecule which regulates TGF- $\beta$ signaling is VE-cadherin. VE-cadherin-deficient endothelial cells demonstrate a loss of TGF- $\beta$-induced inhibition of endothelial cell proliferation and motility $[145,150]$.

TGF- $\beta$ signaling in endothelial cells may contribute to fibrosis via transition to mesenchymal cells (EndMT), giving rise to myofibroblasts in response to fibrogenic injury. EndMT has been reported to contribute to cardiac [151] and renal [152] fibrosis. The generation of mesenchymal profibrotic cells from endothelial cells by this process appears to recapitulate the transdifferentiation of endothelial cells that leads to the formation of the cardiac valves in embryonic development [153]. EndMT is identified by expression of myofibroblasts-like genes [91] in endothelial cells that are expressing or have a "history" of expressing PECAM1/CD31, Tie-1 [151], Tie-2 and CD34 [152, 154]. A difficulty in interpreting these studies is that it is now recognized that Tie-2 is not a specific marker for endothelial cells in that it is also expressed in BM derived hematopoietic cells. Although endothelial cell injury [10] and neovascularization play a critical role in liver fibrosis, the role of EndMT in liver fibrosis is unknown.

3.3.3. TLR4-Signaling. LSEC are exposed to endogenous LPS liver injury. LPS induces upregulation of TLR4 expression in LSECs to facilitate angiogenesis [131]. In vitro, this effect is dependent on Myd88 activation and is associated with secretion of MMP2 by LSEC. In vivo studies have supported this data, demonstrating that TLR4-deficient mice exhibit attenuated angiogenesis and fibrosis [155].

Low, physiological concentrations of endotoxin are continuously present in portal venous blood, and the liver mediates intrinsic signals to develop tolerance [155]. LPS induces the release of IL-10 from LSECs and Kupffer cells and also downregulates $\mathrm{CD}^{+} \mathrm{T}$ cell activation by LSECs through down-modulation of the expression of MHC class II, CD80 and CD86. In contrast, TLR4 activation of professional APC by endotoxin increases $\mathrm{T}$ cell activation. These observations explain why the tolerogenic effect in the liver seems to be related to the continuous exposure of sinusoidal cells to bacterial products from the gut (reviewed in [155]). Following initial activation of LSECs, Kupffer cells are a tolerogenic cellular population contributing to the tolerogenic properties within the liver [155].

3.3.4. $T N F-\alpha-N F \kappa B$. In response to liver injury, release of endogenous LPS mediates release of TNF- $\alpha$, which in turn triggers expression of target genes in LSECs. However, a specific role of $\mathrm{NF} \kappa \mathrm{B}$ in LSECs in the pathogenesis of 
liver fibrosis has not been evaluated [156]. Experiments in transgenic mice overexpressing the IkB- $\alpha$ super-repressor in endothelial cells, have demonstrated that inhibition of the $\mathrm{NF} \kappa \mathrm{B}$ signaling pathway in LPS-stimulated mice causes a defect in expression of endothelial tight junction proteins, and as a result, a loss of integrity of the endothelium and increased vascular permeability [157], suggesting that $\mathrm{NF} \kappa \mathrm{B}$ is responsible for the stress-induced responses of the endothelium to septicemia or TNF- $\alpha$.

3.3.5. Stat3. The role of Stat3 in endothelial cells has not been carefully studied. It has been suggested that Stat3 facilitates protection of endothelial cells (LSEC) exposed to endogenous LPS liver injury and inflammation. IL-6 has a protective effect on hepatic LSECs by activation of Stat3 signaling [158-160]. Consistent with this, endothelialspecific Stat3-deficient mice are more susceptible to alcoholinduced injury, demonstrating a critical function of the endothelium and LSECs in chronic liver injury [160]. Recent study has implicated Stat3 signaling in endothelial cells in mediating dual anti-inflammatory and antiapoptotic functions, of attenuating hepatic inflammation and SEC death during alcoholic liver injury [161].

3.4. Cholangiocytes. Cholangiocytes, the epithelial cells lining intrahepatic bile ducts, are ciliated cells. Each cholangiocyte has a primary cilium consisting of a microtubulebased axoneme and the basal body, centriole-derived, microtubule-organizing center from which the axoneme emerges. Cholangiocyte cilia extend from the apical plasma membrane into the bile duct lumen [162]. Cholangiocytes, the biliary epithelial cells, can be identified by their apical structure and expression of specific keratins, such as K-19 [163]. Cholangiocytes originate from the common epithelial progenitor in the liver during development. Unlike hepatocytes, they lack the ability to regenerate their mass [164]. However, cholangiocytes are capable of proliferation in response to cholestatic liver injury, and this phenomenon has been referred as the ductular reaction [1]. It is believed that cholangiocytes participate in the activation of portal fibroblasts, located in close proximity. Cholangiocytes have been implicated in secretion of a variety of cytokines and factors, which accelerate development of liver fibrosis [165], including NGF, MCP-1 growth factors HGF, VEGF, CTGF, and endothelin-1 [166]. However, it remains unclear if cholangiocytes serve as a significant source of cytokines.

3.4.1. TGF- $\beta$-Smad. Difficulties associated with the isolation and culturing of a pure population of cholangiocytes is a limiting factor in investigating the role of cholangiocytes in fibrogenic liver injury. It has been suggested that similar to hepatocytes, cholangiocytes are capable of differentiation into fibrogenic myofibroblasts via epithelialto-mesenchymal transition (EMT) in response to TGF- $\beta$ induced liver injury $[167,168]$. Although EMT in hepatocytes has been documented in vitro, in vivo studies in adult mice using Cre-lox-based cell fate mapping have not confirmed this finding [97]. Similarly, genetic labeling of
$\mathrm{K} 19^{+}$cholangiocytes has demonstrated that cholangiocytes do not contribute to fibrogenic myofibroblasts in experimental cholestatic liver injury [163, 169]. Moreover, hepatic epithelial cells and their precursors, genetically labeled in alpha-fetoprotein-Cre mice, do not differentiate into fibrogenic myofibroblasts in adult mice $[96,170]$.

3.4.2. TLR Signaling. A few studies have mostly linked TLR signaling in cholangiocytes to anti-microbial immunity [171, 172]. Cholangiocytes may participate in microbe-associated, hepatic proinflammatory responses. In vitro studies of cultured human cholangiocytes suggest that LPS-TLR-signaling pathway activate the small GTPase Ras that mediates cholangiocyte proinflammatory cytokine production and proliferation [172].

3.4.3. NFKB and Stat3 Signaling Pathways. NFkB and/or Stat3 signaling pathways in cholangiocytes have not been specifically evaluated. Meanwhile, conditional inactivation of Stat3 in hepatocytes and cholangiocytes (stat3(Deltahc) of multidrug resistance gene $2 \mathrm{mdr} 2^{(-/)}$mice strongly aggravated bile acid-induced liver injury and fibrosis [120].

3.5. Hepatic Stellate Cells. HSCs are perisinusoidal cells that normally reside in the space of Disse and contain retinoid lipid droplets [173, 174]. Under physiological conditions, HSCs exhibit a quiescent phenotype and express neural markers, such as glial fibrilar acid protein (GFAP), synemin, synaptophysin [1], and nerve growth factor receptor p75 $[175,176]$, secrete hepatocyte growth factor (HGF), and store vitamin A [177]. HSCs are also implicated in phagocytosis and antigen presentation [178, 179]. In response to injury, HSCs have decreased lipid droplets, acquire contractility, and activate into collagen type $\mathrm{I}^{+} \alpha-\mathrm{SMA}^{+}$ myofibroblasts. During development HSCs are derived from the translocation of submesothelial mesenchymal cells from the liver capsule [180].

3.5.1. TGF- $\beta$-Smad2/3 Signaling. TGF- $\beta$ signaling plays a critical role in initiating and promoting the activation of qHSCs into myofibroblasts. Nuclear localization of pSmad2 and pSmad3 is seen in the activated HSC [9]. Transgenic mice have demonstrated that overexpression of TGF- $\beta$ produces liver fibrosis [181], and conditional induction of TGF- $\beta$ has demonstrated that the severity of fibrosis is proportional to the level of produced TGF- $\beta$ [24]. Smad3 is a direct mediator of matrix production in aHSCs. Mice lacking Smad3 are protected from fibrosis $[25,182]$. Activation of TGF- $\beta$ signaling causes transient expression of Smad7, regulated by a feed-back mechanism. Smad7, in turn, inhibits HSC differentiation into fibrogenic myofibroblasts and attenuates experimental fibrosis in vivo [183, 184]. BMP-7, another member of the TGF- $\beta$ superfamily, also acts as a TGF- $\beta$ antagonist and administration of BMP-7 in pharmacological doses attenuates development of kidney and liver fibrosis [101-103].

Although activation/phosphorylation of $S \operatorname{mad} 2 / 3$ is considered to be the main fibrogenic pathway in HSCs, TGF- $\beta 1$ 
has been also found to mediate its profibrogenic action via an alternative ALK1/Smad1 pathway in HSCs by upregulation of Id1 (the inhibitor of differentiation (1) that facilitates HSC activation [185]. TGF- $\beta 1$ controls the transdifferentiation process in HSCs. The recent study, aimed to elucidate TGF$\beta 1$ target genes responsible for fibrogenesis, has analyzed the Smad7-dependent mRNA expression profiles in HSCs, and identified that Id1 protein was strongly reduced by ectopic Smad7 expression in HSCs. In concordance, Id1 overexpression in HSCs enhanced cell activation, while knock-down of Id1 in HSCs inhibited HSC differentiation into myofibroblasts. Treatment of HSCs with TGF$\beta 1$ resulted in Id1 upregulation implicating Id1 to be an alternative but critical mediator of HSC activation into myofibroblasts signaling via TGF- $\beta 1 /$ ALK1/Smad1 pathway [185].

Other factors can facilitate TGF- $\beta$ signaling in HSCs. In particular, stimulation of aHSCs with platelet-derived growth factor (PDGF) and TGF- $\beta$ produces a synergistic effect on migration and expression of MMPs [186, 187]. Moreover, PDGF promotes the activation of HSCs via activation of the PI3K-Akt signaling pathway. PI3K (phosphatidylinositol-3-kinase) activity phosphorylates $\mathrm{PIP}_{2}$ to generate $\mathrm{PIP}_{3}\left(3,4,5\right.$-trisphosphate) [188]. $\mathrm{PIP}_{3}$ binds to the pleckstrin homology domain of Akt, directing it to the cell membrane where it becomes activated by phosphorylation events to initiate cell survival mechanisms. Consistently, inhibition of PI3K activity suppresses cell proliferation and type I collagen gene expression in activated HSCs $[189,190]$. PDGF also activates ERK in HSCs by sequential activation of Ras-Raf-MEK signaling [191] and further facilitates proliferation of aHSCs [192].

The tumor suppressor protein phosphatase and tensin homolog deleted on chromosome ten (PTEN) is a dual specificity protein and lipid phosphatase that dephosphorylates $\mathrm{PIP}_{3}[188,193]$. PTEN is a negative regulator of PI3K and ERK signaling [190]. Overexpression of PTEN attenuates collagen Type I production when aHSCs induces HSC apoptosis. Deletions of PTEN occur during malignant transformation in various tissues [193]. Decreased PTEN expression is also associated with dysregulation of tissue remodeling, such as pulmonary fibrosis, bronchial asthma, and rheumatoid arthritis [194-196]. Since the PI3K/Akt pathway stimulates proliferation and activation of HSCs, inhibiting PTEN promotes liver fibrosis [197].

3.5.2. PDGF Signaling. Platelet-derived growth factor (PDGF) is a powerful mitogen for HSCs. In fibrotic liver, PDGF induces HSC proliferation, synergistically facilitating TGF- $\beta 1$-mediated HSC activation [192]. PDGF signals through the transmembrane receptor tyrosine kinases initiating multiple signaling pathways [198, 199], including activation of the mitogen-activated protein kinase (MAPK) family implicated in cellular proliferation and transmigration. This includes the extracellular signalregulated protein kinase (ERK) pathway and two stressactivated protein kinase (SAPK) pathways: the c-Jun N-terminal kinase (JNK) and the p38 pathway [31].
3.5.3. TLR4-Signaling. LPS activates the NF $\kappa \mathrm{B}$ and JNK/AP1 pathways in aHSCs. LPS enhances expression of the adhesion molecules ICAM-1 and VCAM-1 and TLR2 and the secretion of IL- 8, MCP- 1 , MIP- $1 \alpha$, MIP- $1 \beta$, RANTES, KC, MIP-2, and IP-10 in aHSCs. In turn, LPS downregulates the expression of bone morphogenetic protein (BMP) and activin membrane bound inhibitor (Bambi), a transmembrane suppressor of TGF- $\beta$ signaling (Figure 5). Bambi is a TGF- $\beta$ pseudoreceptor that lacks an intracellular kinase domain, and similar to activin, prevents TGF- $\beta$ signaling. Signaling via TLR4 downregulates Bambi and facilitates TGF- $\beta$ signaling in HSCs. Overexpression of Bambi inhibits HSC activation, while overproduction of a dominant negative form of Bambi enhances TGF- $\beta$ signaling, and induces activation of HSCs [51].

LPS signaling is blocked by inactivation of $\mathrm{NF} \kappa \mathrm{B}$ and JNK, demonstrating the role of NFאB and JNK in TLR4 signaling in HSCs. TLR4 signaling in HSCs is critical for development of liver fibrosis. Bone-marrow chimeric mice with a TLR4 deficiency in recipient liver cells, including HSCs, were resistant to liver fibrosis. Since hepatocytes exhibited no response to LPS in vivo, HSCs were proposed to be the major cell population in the injured liver transmitting TLR4-induced fibrogenic signals [3].

3.5.4. NFkB. TNF- $\alpha$ has a dual role in HSC biology. TNF- $\alpha$ can produce antiapoptotic (via NF $\kappa$ B activation), or proapoptotic (via caspase activation) and antiproliferative responses in HSC $[113,200]$. The later effect is mainly attributed to the ability of $\mathrm{TNF}-\alpha$ to regulate $\mathrm{CD} 95 \mathrm{~L}$ expression.

Activation of HSCs in response to fibrogenic liver injury is associated with increase of the basal $\mathrm{NF} \kappa \mathrm{B}$ activity in comparison with qHSCs $[201,202]$. NF $\kappa$ B promotes antiapoptotic signals in aHSCs predominantly via the classic p65: p50 complex and low levels of a p65 homodimer [200]. Increased basal activity of $\mathrm{NF} \kappa \mathrm{B}$ in activated HSCs is linked to downregulation of $\mathrm{I} \kappa \mathrm{B}-\alpha[201]$. Interestingly, as a result of liver injury, elevated levels of TNF- $\alpha$ further stimulate NF $\kappa \mathrm{B}$ activity. In turn, $\mathrm{NF} \kappa \mathrm{B}$ mediates antiapoptotic functions and protects aHSCs from TNF- $\alpha$-induced apoptosis. TNF- $\alpha$ induced apoptosis of aHSCs can be achieved in the presence of cycloheximide, or pharmacological inhibition of $\mathrm{IkB}$ [200].

3.5.5. Stat3 Signaling. Some Jak2-Stat3-signaling cytokines may have a direct effect on aHSCs by facilitating ECM deposition [203, 204]. Leptin increases collagen production in aHSCs/myofibroblasts in fibrotic liver [205-207] and promotes HSC survival [205]. Treatment with leptin increases the numbers of HSCs in S and G2/M phases of the cell cycle as well as increases cyclin D1 expression. Leptin mediates its function via activation of the Stat3-Jak2 signaling pathway with downstream activation of ERK, AKT and PI3K [113]. Moreover, other agonists, such as PDGF, EGF and HGF, also activate Stat 3 and produce a direct profibrogenic effect on HSCs. As expected, deletion of their corresponding receptors in mice inhibits liver fibrosis $[62,63]$. Taken together, there is 


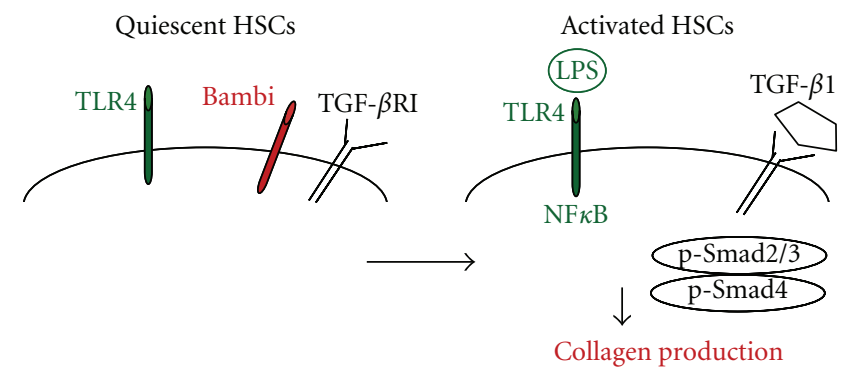

Figure 5: Activation of Hepatic Stellate cells following TLR4 and TGF $\beta$ Receptor cross-talk. In aHSCS, Bambi blocks TGF $\beta$ R activation. TLR4 activation by LPS downregulates BAMBI, so that TGF $\beta 1$ now induces signal transductions of phosphorylated Smad $2 / 3$ and activation of collagen Type I production in HSCs.

emerging evidence that supports a significant role of Stat 3 in stimulating liver fibrosis. However, the specific role of Stat3 in HSC activation using conditional ablation of Stat 3 has not been investigated.

3.6. Portal Fibroblasts (PFs). Portal fibroblasts are defined as spindle shaped cells of mesenchymal origin that are present in the portal tracts. Under normal conditions, they participate in physiological ECM turnover [208-211] and do not express $\alpha$-SMA. Induced mostly by cholestatic liver injury, portal fibroblasts proliferate, though much slower than HSCs [212], and deposit collagen (e.g., type I) around the portal tracts [213].

The mechanisms of liver fibrogenesis after carbon tetrachloride $\left(\mathrm{CCl}_{4}\right)$ or bile duct ligation (BDL) treatment are different. In the $\mathrm{CCl}_{4}$ model, necrosis of hepatocytes and inflammation occurs around centrolobular veins. BDL induces increased biliary pressure and moderate inflammation, causing cytokine secretion by biliary epithelial cells. PFs and HSCs are distributed differently in the hepatic lobule: HSCs resemble pericytes and are located along the sinusoids, in the space of Disse between the endothelium and the hepatocytes, whereas the portal fibroblasts are embedded in the portal tract connective tissue around portal triad [209]. Therefore, the relative activation of HSCs and PFs depend on the model of liver injury [208, 214]. Consistently, PFs have been implicated in pathogenesis of cholestatic liver injury $[7,208]$. Unlike toxic liver injury, in cholestatic liver injury, PFs significantly contribute to a population of fibrogenic myofibroblasts compared to HSCs [209]. Peribiliary myofibroblasts express $\alpha$ SMA, collagen Type I, and PDGF receptor- $\beta$ subunit. In addition, expression of IL-6 is significantly increased in peribiliary myofibroblasts in comparison with activated HSCs [210].

Very little is known about signaling in portal fibroblasts due to the inability to isolate highly purified cells for short term, primary culture. The standard method of isolation of PFs is by outgrowth of peribiliary myofibroblasts from bile duct segments [210, 215]. Differentiating PFs from other fibrogenic myofibroblasts, including aHSCs, is difficult [212]. To date, PFs are distinct from HSCs in that they express elastin (TE-7-positive antigen) and Thy-1.1 (a glycophosphatidylinositol-linked glycoprotein of the outer membrane leaflet described in fibroblasts of several organs) [216-218], do not store retinoids, and do not express desmin or neural markers [219]. Several other proteins have been suggested to be upregulated in PFs (versus HSCs), such are fibulin 1 and 2 [220], gremlin [221]. and cofilin 1 [215]. Moreover, PFs do not express cytoglobin, a protein characteristic for aHSCs [215]. In addition, compared to HSCs, PFs express different TGF- $\beta$ isoforms which may contribute to biliary fibrosis; and distinct from HSCs, PDGF inhibits PFs proliferation and myofibroblastic differentiation $[216,222]$.

3.6.1. TGF- $\beta$-Smad2/3 Signaling. It is anticipated that in response to TGF- $\beta$ signaling, PFs upregulate collagen Type I and activate the Smad2/3 signaling pathway, similar to HSCs and other myofibroblasts [216]. Our general understanding of TGF- $\beta$ signaling suggests that mitogenic signaling synergistically promote the growth and invasion of mesenchymal cells $[84,223]$. Blocking of phosphorylation of Smad2 abrogates the synergistic responses of fibroblasts to TGF- $\beta$ and mitogens $[9,84]$.

\section{Closing Remarks}

In response to chronic injury, every liver cell contributes to the pathophysiology of liver fibrosis. Several key signaling pathways have emerged that are critical for liver fibrosis. The TGF- $\beta /$ Smad pathway has been well characterized and demonstrated to affect every liver cell type. More recent studies have demonstrated key roles for other pathways, including TLR4 and Jak/Stat3 in hepatic fibrosis. Furthermore, there is cross-talk between these fibrogenic pathways. For example, activating TLR4 signaling potentiates the TFG- $\beta /$ Smad pathway. Although the TGF- $\beta$ pathway might be too important in physiological homeostasis to block as a therapeutic intervention, targeting new cross-talking pathways may provide novel approaches to the treatment of liver fibrosis.

\section{Abbreviations}

HSCs: Hepatic stellate cells

qHSCs: Quiescent HSCs

aHSCs: Activated HSCs

CCl: Carbon tetrachloride

BDL: Bile duct ligation

$\alpha$-SMA: $\alpha$-smooth muscle actin

ECM: Extracellular matrix

SMA: $\quad \alpha$-smooth muscle protein

TGF- $\beta 1$ : Transforming growth factor- $\beta 1$

LPS: Lipopolysaccharide

LSECs: Liver sinusoidal endothelial cells. 


\section{Authors' Contribution}

M. Cong, K. Iwaisako, C. Jiang equally contributed to the writing of the paper, designed and provided critical revision of the paper, T. Kisseleva designed and wrote the paper.

\section{Conflict of Interests}

The authors declare no conflict of interests.

\section{Acknowledgments}

The paper received funding supported by the National Institutes of Health (GM41804, AA15055, DK72237, and AI077780) and the American Liver Foundation (2006 Liver Scholar Research Award). It is also supported by Grants from David Brenner (NIH RO1 DK090962-01, NIH RO1 DK072237-06, NIH RO1 GM041804-24, and NIH P50 AA011999-13).

\section{References}

[1] R. Bataller and D. A. Brenner, "Liver fibrosis," Journal of Clinical Investigation, vol. 115, no. 2, pp. 209-218, 2005.

[2] T. Kisseleva and D. A. Brenner, "Fibrogenesis of parenchymal organs," Proceedings of the American Thoracic Society, vol. 5, no. 3, pp. 338-342, 2008.

[3] E. Seki, S. De Minicis, C. H. Österreicher et al., "TLR4 enhances TGF- $\beta$ signaling and hepatic fibrosis," Nature Medicine, vol. 13, no. 11, pp. 1324-1332, 2007.

[4] S. De Minicis, E. Seki, H. Uchinami et al., "Gene expression profiles during hepatic stellate cell activation in culture and in vivo," Gastroenterology, vol. 132, no. 5, pp. 1937-1946, 2007.

[5] S. L. Friedman, F. J. Roll, J. Boyles, and D. M. Bissell, "Hepatic lipocytes: the principal collagen-producing cells of normal rat liver," Proceedings of the National Academy of Sciences of the United States of America, vol. 82, no. 24, pp. 8681-8685, 1985.

[6] R. G. Wells, "The role of matrix stiffness in regulating cell behavior," Hepatology, vol. 47, no. 4, pp. 1394-1400, 2008.

[7] A. Desmoulière, I. Darby, A. M. A. Costa et al., "Extracellular matrix deposition, lysyl oxidase expression, and myofibroblastic differentiation during the initial stages of cholestatic fibrosis in the rat," Laboratory Investigation, vol. 76, no. 6, pp. 765-778, 1997.

[8] A. Desmoulière, "Hepatic stellate cells: the only cells involved in liver fibrogenesis? A dogma challenged," Gastroenterology, vol. 132, no. 5, pp. 2059-2062, 2007.

[9] K. Matsuzaki, "Smad phosphoisoform signals in acute and chronic liver injury: similarities and differences between epithelial and mesenchymal cells," Cell and Tissue Research, pp. 1-19, 2011.

[10] T. Kisseleva and D. A. Brenner, "Mechanisms of fibrogenesis," Experimental Biology and Medicine, vol. 233, no. 2, pp. 109$122,2008$.

[11] A. B. Roberts, U. I. Heine, K. C. Flanders, and M. B. Sporn, "Transforming growth factor- $\beta$. Major role in regulation of extracellular matrix," Annals of the New York Academy of Sciences, vol. 580, pp. 225-232, 1990.

[12] A. B. Roberts, K. C. Flanders, U. I. Heine et al., "Transforming growth factor-beta: multifunctional regulator of differentiation and development," Philosophical transactions of the Royal Society of London, vol. 327, no. 1239, pp. 145-154, 1990.
[13] X. Guo and S. Y. Chen, "Transforming growth factor-beta and smooth muscle differentiation," World Journal of Biological Chemistry, vol. 26, no. 3, pp. 41-52, 2012.

[14] N. Schuster and K. Krieglstein, "Mechanisms of TGF- $\beta$ mediated apoptosis," Cell and Tissue Research, vol. 307, no. 1, pp. 1-14, 2002.

[15] A. K. Ghosh and J. Varga, "The transcriptional coactivator and acetyltransferase p300 in fibroblast biology and fibrosis," Journal of Cellular Physiology, vol. 213, no. 3, pp. 663-671, 2007.

[16] D. Sheppard, "Transforming growth factor beta: a central modulator of pulmonary and airway inflammation and fibrosis," Proceedings of the American Thoracic Society, vol. 3, no. 5, pp. 413-417, 2006.

[17] E. S. White, F. E. Baralle, and A. F. Muro, "New insights into form and function of fibronectin splice variants," Journal of Pathology, vol. 216, no. 1, pp. 1-14, 2008.

[18] Z. Yang, Z. Mu, B. Dabovic et al., "Absence of integrinmediated TGF $\beta 1$ activation in vivo recapitulates the phenotype of TGF $\beta 1$-null mice," Journal of Cell Biology, vol. 176, no. 6, pp. 787-793, 2007.

[19] J. E. Murphy-Ullrich and M. Poczatek, "Activation of latent TGF- $\beta$ by thrombospondin-1: mechanisms and physiology," Cytokine and Growth Factor Reviews, vol. 11, no. 1-2, pp. 5969,2000

[20] J. S. Munger, X. Huang, H. Kawakatsu et al., "The integrin $\alpha \mathrm{v} \beta 6$ binds and activates latent TGF $\beta 1$ : a mechanism for regulating pulmonary inflammation and fibrosis," Cell, vol. 96, no. 3, pp. 319-328, 1999.

[21] K. Breitkopf, S. Haas, E. Wiercinska, M. V. Singer, and S. Dooley, "Anti-TGF- $\beta$ strategies for the treatment of chronic liver disease," Alcoholism, vol. 29, supplement 11, pp. 121S131S, 2005.

[22] K. Breitkopf, P. Godoy, L. Ciuclan, M. V. Singer, and S. Dooley, "TGF- $\beta /$ Smad signaling in the injured liver," Zeitschrift fur Gastroenterologie, vol. 44, no. 1, pp. 57-66, 2006.

[23] G. J. Thomas, M. L. Nyström, and J. F. Marshall, “ $\alpha v \beta 6$ integrin in wound healing and cancer of the oral cavity," Journal of Oral Pathology and Medicine, vol. 35, no. 1, pp. 1-10, 2006.

[24] E. Ueberham, R. Löw, U. Ueberham, K. Schönig, H. Bujard, and R. Gebhardt, "Conditional tetracycline-regulated expression of TGF- $\beta 1$ in liver of transgenic mice leads to reversible intermediary fibrosis," Hepatology, vol. 37, no. 5, pp. 10671078, 2003.

[25] G. Latella, A. Vetuschi, R. Sferra et al., "Targeted disruption of Smad3 confers resistance to the development of dimethylnitrosamine-induced hepatic fibrosis in mice," Liver International, vol. 29, no. 7, pp. 997-1009, 2009.

[26] A. Leask and D. J. Abraham, "TGF- $\beta$ signaling and the fibrotic response," FASEB Journal, vol. 18, no. 7, pp. 816-827, 2004.

[27] F. Chua, S. E. Dunsmore, P. H. Clingen et al., "Mice lacking neutrophil elastase are resistant to bleomycin-induced pulmonary fibrosis," American Journal of Pathology, vol. 170, no. 1, pp. 65-74, 2007.

[28] Y. Shi and J. Massagué, "Mechanisms of TGF- $\beta$ signaling from cell membrane to the nucleus," Cell, vol. 113, no. 6, pp. 685-700, 2003.

[29] E. Arciniegas, M. G. Frid, I. S. Douglas, and K. R. Stenmark, "Perspectives on endothelial-to-mesenchymal transition: potential contribution to vascular remodeling in chronic pulmonary hypertension," American Journal of Physiology-Lung Cellular and Molecular Physiology, vol. 293, no. 1, pp. L1-L8, 2007. 
[30] J. L. Wrana, "Regulation of Smad activity," Cell, vol. 100, no. 2, pp. 189-192, 2000.

[31] K. Yoshida and K. Matsuzaki, "Differential regulation of TGF-beta/Smad signaling in hepatic stellate cells between acute and chronic liver injuries," Frontiers in Physiology, vol. 3, p. 53, 2012.

[32] D. Onichtchouk, Y. G. Chen, R. Dosch et al., "Silencing of TGF- $\beta$ signalling by the pseudoreceptor BAMBI," Nature, vol. 401, no. 6752, pp. 480-485, 1999.

[33] W. A. Border, N. A. Noble, T. Yamamoto et al., "Natural inhibitor of transforming growth factor- $\beta$ protects against scarring in experimental kidney disease," Nature, vol. 360, no. 6402, pp. 361-364, 1992.

[34] S. Oertelt, Z. X. Lian, C. M. Cheng et al., "Anti-mitochondrial antibodies and primary biliary cirrhosis in TGF- $\beta$ receptor II dominant-negative mice," Journal of Immunology, vol. 177, no. 3, pp. 1655-1660, 2006.

[35] M. Sato, Y. Muragaki, S. Saika, A. B. Roberts, and A. Ooshima, "Targeted disruption of TGF- $\beta 1 /$ Smad 3 signaling protects against renal tubulointerstitial fibrosis induced by unilateral ureteral obstruction," Journal of Clinical Investigation, vol. 112, no. 10, pp. 1486-1494, 2003.

[36] S. Dooley, B. Delvoux, M. Streckert et al., "Transforming growth factor $\beta$ signal transduction in hepatic stellate cells via Smad2/3 phosphorylation, a pathway that is abrogated during in vitro progression to myofibroblasts: TGF $\beta$ signal transduction during transdifferentiation of hepatic stellate cells," FEBS Letters, vol. 502, no. 1-2, pp. 4-10, 2001.

[37] T. Hayashida, "Integrins modulate cellular fibrogenesis at multiple levels; Regulation of TGF- $\beta$ signaling.", Endocrine, metabolic \& immune disorders drug targets, vol. 10, no. 4, pp. 302-319, 2010.

[38] R. Derynck and Y. E. Zhang, "Smad-dependent and Smadindependent pathways in TGF- $\beta$ family signalling," Nature, vol. 425, no. 6958, pp. 577-584, 2003.

[39] V. F. S. Shih, R. Tsui, A. Caldwell, and A. Hoffmann, "A single $\mathrm{NF} \kappa \mathrm{B}$ system for both canonical and non-canonical signaling," Cell Research, vol. 21, no. 1, pp. 86-102, 2011.

[40] A. S. Baldwin Jr, "The NF-kappa B and I kappa B proteins: new discoveries and insights," Annual Review of Immunology, vol. 14, pp. 649-683, 1996.

[41] S. Ghosh, M. J. May, and E. B. Kopp, "NF- $\kappa$ B and rel proteins: evolutionarily conserved mediators of immune responses," Annual Review of Immunology, vol. 16, pp. 225-260, 1998.

[42] M. Karin and Y. Ben-Neriah, "Phosphorylation meets ubiquitination: the control of NF- $\kappa \mathrm{B}$ activity," Annual Review of Immunology, vol. 18, pp. 621-663, 2000.

[43] C. Scheidereit, "I $\kappa \mathrm{B}$ kinase complexes: gateways to NF- $\kappa \mathrm{B}$ activation and transcription," Oncogene, vol. 25, no. 51, pp. 6685-6705, 2006.

[44] D. Rudolph, W. C. Yeh, A. Wakeham et al., "Severe liver degeneration and lack of NF-kappaB activation in NEMO/ IKKgamma-deficient mice," Genes \& Development, vol. 14, no. 7, pp. 854-862, 2000.

[45] Q. Li, D. Van Antwerp, F. Mercurio, K. F. Lee, and I. M. Verma, "Severe liver degeneration in mice lacking the $\mathrm{I} \kappa \mathrm{B}$ kinase 2 gene," Science, vol. 284, no. 5412, pp. 321-325, 1999.

[46] A. A. Beg, W. C. Sha, R. T. Bronson, S. Ghosh, and D. Baltimore, "Embryonic lethality and liver degeneration in mice lacking the RelA component of NF- $\kappa \mathrm{B}$," Nature, vol. 376, no. 6536, pp. 167-170, 1995.

[47] T. Luedde, J. Heinrichsdorff, R. De Lorenzi, R. De Vos, T. Roskams, and M. Pasparakis, "IKK1 and IKK2 cooperate to maintain bile duct integrity in the liver," Proceedings of the
National Academy of Sciences of the United States of America, vol. 105, no. 28, pp. 9733-9738, 2008.

[48] L. Yin, L. Wu, H. Wesche et al., "Defective lymphotoxin$\beta$ receptor-induced NF- $\kappa \mathrm{B}$ transcriptional activity in NIKdeficient mice," Science, vol. 291, no. 5511, pp. 2162-2165, 2001.

[49] Z. B. Yilmaz, D. S. Weih, V. Sivakumar, and F. Weih, "RelB is required for Peyer's patch development: differential regulation of p52-RelB by lymphotoxin and TNF," EMBO Journal, vol. 22, no. 1, pp. 121-130, 2003.

[50] D. Yang and J. J. Oppenheim, "Antimicrobial proteins act as "Alarmins" in joint immune defense," Arthritis and Rheumatism, vol. 50, no. 11, pp. 3401-3403, 2004.

[51] T. Aoyama, Y. H. Paik, and E. Seki, "Toll-like receptor signaling and liver fibrosis," Gastroenterology Research and Practice, vol. 2010, Article ID 192543, 8 pages, 2010.

[52] E. G. Pamer, "TLR polymorphisms and the risk of invasive fungal infections," New England Journal of Medicine, vol. 359, no. 17, pp. 1836-1838, 2008.

[53] A. W. Yan and B. Schnabl, "Bacterial translocation and changes in the intestinal microbiome associated with alcoholic liver disease," World Journal of Hepatology, vol. 4, no. 4, pp. 110-118, 2012.

[54] K. Iwaisako, M. Haimerl, Y. H. Paik et al., "et al. Protection from liver fibrosis by a peroxisome proliferator-activated receptor delta agonist," Proceedings of the National Academy of Sciences of the United States of America, vol. 109, no. 21, pp. 1369-1376, 2012.

[55] D. E. Fouts, M. Torralba, K. E. Nelson, D. A. Brenner, and B. Schnabl, "Bacterial translocation and changes in the intestinal microbiome in mouse models of liver disease," Journal of Hepatology, vol. 56, no. 6, pp. 1283-1292, 2012.

[56] E. Seki and B. Schnabl, "Role of innate immunity and the microbiota in liver fibrosis: crosstalk between the liver and gut," Journal of Physiology, vol. 590, no. 3, pp. 447-458, 2012.

[57] A. Albillos, A. D. la Hera, M. González et al., "Increased lipopolysaccharide binding protein in cirrhotic patients with marked immune and hemodynamic derangement," Hepatology, vol. 37, no. 1, pp. 208-217, 2003.

[58] F. Isayama, I. N. Hines, M. Kremer et al., "LPS signaling enhances hepatic fibrogenesis caused by experimental cholestasis in mice," American Journal of PhysiologyGastrointestinal and Liver Physiology, vol. 290, no. 6, pp. G1318-G1328, 2006.

[59] E. S. White and A. F. Muro, "Fibronectin splice variants: understanding their multiple roles in health and disease using engineered mouse models," IUBMB Life, vol. 63, no. 7, pp. 538-546, 2011.

[60] Y. Okamura, M. Watari, E. S. Jerud et al., "The extra domain A of fibronectin activates toll-like receptor 4," Journal of Biological Chemistry, vol. 276, no. 13, pp. 10229-10233, 2001.

[61] X. H. Xu, P. K. Shah, E. Faure et al., "Toll-like receptor-4 is expressed by macrophages in murine and human lipid-rich atherosclerotic plaques and upregulated by oxidized LDL," Circulation, vol. 104, no. 25, pp. 3103-3108, 2001.

[62] T. Kisseleva, S. Bhattacharya, J. Braunstein, and C. W. Schindler, "Signaling through the JAK/STAT pathway, recent advances and future challenges," Gene, vol. 285, no. 1-2, pp. $1-24,2002$.

[63] B. Gao, "Cytokines, STATs and liver disease," Cellular \& Molecular Immunology, vol. 2, no. 2, pp. 92-100, 2005.

[64] S. Akira, Y. Nishio, M. Inoue et al., "Molecular cloning of APRF, a novel IFN-stimulated gene factor 3 p91-related transcription factor involved in the gp130-mediated signaling pathway," Cell, vol. 77, no. 1, pp. 63-71, 1994. 
[65] T. Bowman, R. Garcia, J. Turkson, and R. Jove, "STATs in oncogenesis," Oncogene, vol. 19, no. 21, pp. 2474-2488, 2000.

[66] K. Takeda, K. Noguchi, W. Shi et al., "Targeted disruption of the mouse Stat3 gene leads to early embryonic lethality," Proceedings of the National Academy of Sciences of the United States of America, vol. 94, no. 8, pp. 3801-3804, 1997.

[67] K. Takeda, T. Kaisho, N. Yoshida, J. Takeda, T. Kishimoto, and S. Akira, "Stat3 activation is responsible for IL-6-dependent $\mathrm{T}$ cell proliferation through preventing apoptosis: generation and characterization of T cell- specific stat3-deficient mice," Journal of Immunology, vol. 161, no. 9, pp. 4652-4660, 1998.

[68] K. Takeda, B. E. Clausen, T. Kaisho et al., "Enhanced Th1 activity and development of chronic enterocolitis in mice devoid of stat 3 in macrophages and neutrophils," Immunity, vol. 10, no. 1, pp. 39-49, 1999.

[69] R. S. Chapman, P. C. Lourenco, E. Tonner et al., "Suppression of epithelial apoptosis and delayed mammary gland involution in mice with a conditional knockout of Stat3," Genes and Development, vol. 13, no. 19, pp. 2604-2616, 1999.

[70] T. Alonzi, D. Maritano, B. Gorgoni, G. Rizzuto, C. Libert, and V. Poli, "Essential role of STAT3 in the control of the acutephase response as revealed by inducible gene activation in the liver," Molecular and Cellular Biology, vol. 21, no. 5, pp. 16211632, 2001.

[71] W. Plum, D. F. Tschaharganeh, D. C. Kroy et al., "Lack of glycoprotein 130/signal transducer and activator of transcription 3-mediated signaling in hepatocytes enhances chronic liver injury and fibrosis progression in a model of sclerosing cholangitis," American Journal of Pathology, vol. 176, no. 5, pp. 2236-2246, 2010.

[72] T. A. Wynn, "Fibrotic disease and the $\mathrm{T}(\mathrm{H}) 1 / \mathrm{T}(\mathrm{H}) 2$ paradigm," Nature Reviews Immunology, vol. 4, no. 8, pp. 583594, 2004.

[73] K. Kovalovich, R. A. Deangelis, W. Li, E. E. Furth, G. Ciliberto, and R. Taub, "Increased toxin-induced liver injury and fibrosis in interleukin-6- deficient mice," Hepatology, vol. 31, no. 1, pp. 149-159, 2000.

[74] H. Louis, O. Le Moine, M. Goldman, and J. Devière, "Modulation of liver injury by interleukin-10," Acta GastroEnterologica Belgica, vol. 66, no. 1, pp. 7-14, 2003.

[75] K. L. Streetz, T. Wüstefeld, C. Klein et al., "Lack of gp130 expression in hepatocytes promotes liver injury," Gastroenterology, vol. 125, no. 2, pp. 532-543, 2003.

[76] S. H. Ki, O. Park, M. Zheng et al., "Interleukin-22 treatment ameliorates alcoholic liver injury in a murine model of chronic-binge ethanol feeding: role of signal transducer and activator of transcription 3.," Hepatology, vol. 52, no. 4, pp. 1291-1300, 2010.

[77] L. A. Zenewicz, G. D. Yancopoulos, D. M. Valenzuela, A. J. Murphy, M. Karow, and R. A. Flavell, "Interleukin-22 but not interleukin-17 provides protection to hepatocytes during acute liver inflammation," Immunity, vol. 27, no. 4, pp. 647659, 2007.

[78] H. Wang, F. Lafdil, X. Kong, and B. Gao, "Signal transducer and activator of transcription 3 in liver diseases: a novel therapeutic target," International Journal of Biological Sciences, vol. 7, no. 5, pp. 536-550, 2011.

[79] T. K. Kuo, S. P. Hung, C. H. Chuang et al., "Stem cell therapy for liver disease: parameters governing the success of using bone marrow mesenchymal stem cells," Gastroenterology, vol. 134, no. 7, pp. 2111-e3, 2008.

[80] D. E. Cressman, L. E. Greenbaum, R. A. DeAngelis et al., "Liver failure and defective hepatocyte regeneration in interleukin-6- deficient mice," Science, vol. 274, no. 5291, pp. 1379-1383, 1996.

[81] S. Hata, M. Namae, and H. Nishina, "Liver development and regeneration: from laboratory study to clinical therapy," Development Growth and Differentiation, vol. 49, no. 2, pp. 163-170, 2007.

[82] G. K. Michalopoulos and M. C. DeFrances, "Liver regeneration," Science, vol. 276, no. 5309, pp. 60-65, 1997.

[83] S. Kawamata, K. Matsuzaki, M. Murata et al., "Oncogenic Smad3 signaling induced by chronic inflammation is an early event in ulcerative colitis-associated carcinogenesis," Inflammatory Bowel Diseases, vol. 17, no. 3, pp. 683-695, 2011.

[84] K. Matsuzaki, C. Kitano, M. Murata et al., "Smad2 and Smad3 phosphorylated at both linker and $\mathrm{COOH}$-terminal regions transmit malignant TGF- $\beta$ signal in later stages of human colorectal cancer," Cancer Research, vol. 69, no. 13, pp. 5321-5330, 2009.

[85] J. W. Harper, G. R. Adami, N. Wei, K. Keyomarsi, and S. J. Elledge, "The p21 Cdk-interacting protein Cip1 is a potent inhibitor of G1 cyclin- dependent kinases," Cell, vol. 75, no. 4, pp. 805-816, 1993.

[86] M. Date, K. Matsuzaki, M. Matsushita et al., "Diffrential expression of transforming growth factor- $\beta$ and its receptors in hepatocytes and nonparenchymal cells of rat liver after CCl4 administration," Journal of Hepatology, vol. 28, no. 4, pp. 572-581, 1998.

[87] M. Date, K. Matsuzaki, M. Matsushita, Y. Tahashi, K. Sakitani, and K. Inoue, "Differential regulation of activin A for hepatocyte growth and fibronectin synthesis in rat liver injury," Journal of Hepatology, vol. 32, no. 2, pp. 251-260, 2000.

[88] K. Matsuzaki, M. Murata, K. Yoshida et al., "Chronic inflammation associated with hepatitis $C$ virus infection perturbs hepatic transforming growth factor $\beta$ signaling, promoting cirrhosis and hepatocellular carcinoma," Hepatology, vol. 46, no. 1, pp. 48-57, 2007.

[89] H. Nagata, E. Hatano, M. Tada et al., "Inhibition of cJun NH2-terminal kinase switches Smad3 signaling from oncogenesis to tumor-suppression in rat hepatocellular carcinoma," Hepatology, vol. 49, no. 6, pp. 1944-1953, 2009.

[90] J. Zavadil, M. Bitzer, D. Liang et al., "Genetic programs of epithelial cell plasticity directed by transforming growth factor- $\beta$," Proceedings of the National Academy of Sciences of the United States of America, vol. 98, no. 12, pp. 6686-6691, 2001.

[91] M. Zeisberg and E. G. Neilson, "Biomarkers for epithelialmesenchymal transitions," Journal of Clinical Investigation, vol. 119, no. 6, pp. 1429-1437, 2009.

[92] M. Iwano, D. Plieth, T. M. Danoff, C. Xue, H. Okada, and E. G. Neilson, "Evidence that fibroblasts derive from epithelium during tissue fibrosis," Journal of Clinical Investigation, vol. 110, no. 3, pp. 341-350, 2002.

[93] R. Kalluri and E. G. Neilson, "Epithelial-mesenchymal transition and its implications for fibrosis," Journal of Clinical Investigation, vol. 112, no. 12, pp. 1776-1784, 2003.

[94] E. G. Neilson, "Mechanisms of disease: fibroblasts_a new look at an old problem," Nature Clinical Practice Nephrology, vol. 2, no. 2, pp. 101-108, 2006.

[95] M. Zeisberg, C. Yang, M. Martino et al., "Fibroblasts derive from hepatocytes in liver fibrosis via epithelial to mesenchymal transition," Journal of Biological Chemistry, vol. 282, no. 32, pp. 23337-23347, 2007. 
[96] T. Kisseleva and D. A. Brenner, "Is it the end of the line for the EMT?" Hepatology, vol. 53, no. 5, pp. 1433-1435, 2011.

[97] K. Taura, K. Miura, K. Iwaisako et al., "Hepatocytes do not undergo epithelial-mesenchymal transition in liver fibrosis in mice," Hepatology, vol. 51, no. 3, pp. 1027-1036, 2010.

[98] C. Gebhardt, J. Németh, P. Angel, and J. Hess, "S100A8 and S100A9 in inflammation and cancer," Biochemical Pharmacology, vol. 72, no. 11, pp. 1622-1631, 2006.

[99] W. Nacken, J. Roth, C. Sorg, and C. Kerkhoff, "S100A9/ S100A8: myeloid representatives of the $S 100$ protein family as prominent players in innate immunity," Microscopy research and technique, vol. 60, no. 6, pp. 569-580, 2003.

[100] C. H. Osterreicher, M. Penz-Osterreicher, S. I. Grivennikov et al., "Fibroblast-specific protein 1 identifies an inflammatory subpopulation of macrophages in the liver," Proceedings of the National Academy of Sciences of the United States of America, vol. 108, no. 1, pp. 308-313, 2011.

[101] K. Kinoshita, Y. Iimuro, K. Otogawa et al., "Adenovirusmediated expression of BMP-7 suppresses the development of liver fibrosis in rats," Gut, vol. 56, no. 5, pp. 706-714, 2007.

[102] R. Weiskirchen, S. K. Meurer, O. A. Gressner, J. Herrmann, E. Borkham-Kamphorst, and A. M. Gressner, "BMP-7 as antagonist of organ fibrosis," Frontiers in Bioscience, vol. 14, no. 13, pp. 4992-5012, 2009.

[103] C. N. Jones, N. Tuleuova, J. Y. Lee et al., "Cultivating hepatocytes on printed arrays of HGF and BMP7 to characterize protective effects of these growth factors during in vitro alcohol injury," Biomaterials, vol. 31, no. 23, pp. 5936-5944, 2010.

[104] L. Zhu, L. Wang, X. Wang et al., "Hepatic deletion of Smad7 in mouse leads to spontaneous liver dysfunction and aggravates alcoholic liver injury," PLoS ONE, vol. 6, no. 2, Article ID e17415, 2011.

[105] I. N. Crispe, “The liver as a lymphoid organ," Annual Review of Immunology, vol. 27, pp. 147-163, 2009.

[106] E. Seki and D. A. Brenner, "Toll-like receptors and adaptor molecules in liver disease: update," Hepatology, vol. 48, no. 1, pp. 322-335, 2008.

[107] S. Liu, D. J. Gallo, A. M. Green et al., "Role of toll-like receptors in changes in gene expression and NF- $\kappa \mathrm{B}$ activation in mouse hepatocytes stimulated with lipopolysaccharide," Infection and Immunity, vol. 70, no. 7, pp. 3433-3442, 2002.

[108] Y. Chen and R. Sun, "Toll-like receptors in acute liver injury and regeneration," International Immunopharmacology, vol. 11, no. 10, pp. 1433-1441, 2011.

[109] T. Matsumura, A. Ito, T. Takii, H. Hayashi, and K. Onozaki, "Endotoxin and cytokine regulation of toll-like receptor (TLR) 2 and TLR4 gene expression in murine liver and hepatocytes," Journal of Interferon and Cytokine Research, vol. 20, no. 10, pp. 915-921, 2000.

[110] J. S. Campbell, K. J. Riehle, J. T. Brooling, R. L. Bauer, C. Mitchell, and N. Fausto, "Proinflammatory cytokine production in liver regeneration is Myd88-dependent, but independent of Cd14, Tlr2, and Tlr4," Journal of Immunology, vol. 176, no. 4, pp. 2522-2528, 2006.

[111] E. Burstein and C. S. Duckett, "Dying for NF- $\kappa$ B? Control of cell death by transcriptional regulation of the apoptotic machinery," Current Opinion in Cell Biology, vol. 15, no. 6, pp. 732-737, 2003.

[112] V. Lehmann, M. A. Freudenberg, and C. Galanos, "Lethal toxicity of lipopolysaccharide and tumor necrosis factor in normal and D-galactosamine-treated mice," Journal of Experimental Medicine, vol. 165, no. 3, pp. 657-663, 1987.
[113] A. M. Elsharkawy, F. Oakley, and D. A. Mann, "The role and regulation of hepatic stellate cell apoptosis in reversal of liver fibrosis," Apoptosis, vol. 10, no. 5, pp. 927-939, 2005.

[114] S. Akira, "Roles of STAT3 defined by tissue-specific gene targeting," Oncogene, vol. 19, no. 21, pp. 2607-2611, 2000.

[115] W. Waelput, A. Verhee, D. Broekaert et al., "Identification and expression analysis of leptin-regulated immediate early response and late target genes," Biochemical Journal, vol. 348, no. 1, pp. 55-61, 2000.

[116] K. Terui and M. Ozaki, "The role of STAT3 in liver regeneration,” Drugs of Today, vol. 41, no. 7, pp. 461-469, 2005.

[117] W. Li, X. Liang, C. Kellendonk, V. Poli, and R. Taub, "STAT3 contributes to the mitogenic response of hepatocytes during liver regeneration," Journal of Biological Chemistry, vol. 277, no. 32, pp. 28411-28417, 2002.

[118] M. Fujiyoshi and M. Ozaki, "Molecular mechanisms of liver regeneration and protection for treatment of liver dysfunction and diseases," Journal of Hepato-Biliary-Pancreatic Sciences, vol. 18, no. 1, pp. 13-22, 2011.

[119] K. Kovalovich, W. Li, R. DeAngelis, L. E. Greenbaum, G. Ciliberto, and R. Taub, "Interleukin-6 protects against fas-mediated death by establishing a critical level of antiapoptotic hepatic proteins FLIP, Bcl-2, and Bcl-xL," Journal of Biological Chemistry, vol. 276, no. 28, pp. 26605-26613, 2001.

[120] M. Mair, G. Zollner, D. Schneller et al., "Signal transducer and activator of transcription 3 protects from liver injury and fibrosis in a mouse model of sclerosing cholangitis," Gastroenterology, vol. 138, no. 7, pp. 2499-2508, 2010.

[121] S. Haga, K. Terui, H. Q. Zhang et al., "Stat3 protects against Fas-induced liver injury by redox-dependent and- independent mechanisms," Journal of Clinical Investigation, vol. 112, no. 7, pp. 989-998, 2003.

[122] K. Terui, S. Enosawa, S. Haga et al., "Stat3 confers resistance against hypoxia/reoxygenation-induced oxidative injury in hepatocytes through upregulation of Mn-SOD," Journal of Hepatology, vol. 41, no. 6, pp. 957-965, 2004.

[123] Y. Zi, Y. Wang, P. S. Wiegmann et al., "In vivo treatment of HCV core-positive HepG2 cells with the transfer of recombinant caspase-3 using a 2'-5' OAS promoter," Molecular Medicine Reports, vol. 5, no. 3, pp. 631-636, 2012.

[124] T. Aoyama, S. Inokuchi, D. A. Brenner, and E. Seki, "CX3CL1-CX3CR1 interaction prevents carbon tetrachloride-induced liver inflammation and fibrosis in mice.," Hepatology (Baltimore, Md.), vol. 52, no. 4, pp. 1390-1400, 2010.

[125] E. Seki, S. De Minicis, S. Inokuchi et al., "CCR2 promotes hepatic fibrosis in mice," Hepatology, vol. 50, no. 1, pp. 185197, 2009.

[126] E. Seki, H. Tsutsui, H. Nakano et al., "Lipopolysaccharideinduced IL-18 secretion from murine Kupffer cells independently of myeloid differentiation factor 88 that is critically involved in induction of production of IL-12 and IL-1 $\beta$," Journal of Immunology, vol. 166, no. 4, pp. 2651-2657, 2001.

[127] B. Gao, E. Seki, D. A. Brenner et al., "Innate immunity in alcoholic liver disease," American Journal of Physiology-Gastrointestinal and Liver Physiology, vol. 300, no. 4, pp. G516G525, 2011.

[128] H. Yasukawa, M. Ohishi, H. Mori et al., "IL-6 induces an anti-inflammatory response in the absence of SOCS3 in macrophages," Nature Immunology, vol. 4, no. 6, pp. 551556, 2003.

[129] Y. Iwakiri, "Endothelial dysfunction in the regulation of cirrhosis and portal hypertension," Liver International, vol. 32, no. 2, pp. 199-213, 2011. 
[130] D. Thabut and V. Shah, "Intrahepatic angiogenesis and sinusoidal remodeling in chronic liver disease: new targets for the treatment of portal hypertension?" Journal of Hepatology, vol. 53, no. 5, pp. 976-980, 2010.

[131] K. Jagavelu, C. Routray, U. Shergill, S. P. O’Hara, W. Faubion, and V. H. Shah, "Endothelial cell toll-like receptor 4 regulates fibrosis-associated angiogenesis in the liver," Hepatology, vol. 52, no. 2, pp. 590-601, 2010.

[132] Y. Iwakiri and R. J. Groszmann, "Vascular endothelial dysfunction in cirrhosis," Journal of Hepatology, vol. 46, no. 5, pp. 927-934, 2007.

[133] T. A. Wynn, "Common and unique mechanisms regulate fibrosis in various fibroproliferative diseases," Journal of Clinical Investigation, vol. 117, no. 3, pp. 524-529, 2007.

[134] Z. K. Otrock, R. A. R. Mahfouz, J. A. Makarem, and A. I. Shamseddine, "Understanding the biology of angiogenesis: review of the most important molecular mechanisms," Blood Cells, Molecules, and Diseases, vol. 39, no. 2, pp. 212-220, 2007.

[135] D. H. Kang and R. J. Johnson, "Vascular endothelial growth factor: a new player in the pathogenesis of renal fibrosis," Current Opinion in Nephrology and Hypertension, vol. 12, no. 1, pp. 43-49, 2003.

[136] M. Ushio-Fukai, "VEGF signaling through NADPH oxidasederived ROS," Antioxidants and Redox Signaling, vol. 9, no. 6, pp. 731-739, 2007.

[137] K. Taura, S. De Minicis, E. Seki et al., "Hepatic stellate cells secrete angiopoietin 1 that induces angiogenesis in liver fibrosis," Gastroenterology, vol. 135, no. 5, pp. 1729-1738, 2008.

[138] T. Makinde, R. F. Murphy, and D. K. Agrawal, "Immunomodulatory role of vascular endothelial growth factor and angiopoietin-1 in airway remodeling," Current Molecular Medicine, vol. 6, no. 8, pp. 831-841, 2006.

[139] M. Fernandez, M. Mejias, B. Angermayr, J. C. GarciaPagan, J. Rodés, and J. Bosch, "Inhibition of VEGF receptor2 decreases the development of hyperdynamic splanchnic circulation and portal-systemic collateral vessels in portal hypertensive rats," Journal of Hepatology, vol. 43, no. 1, pp. 98-103, 2005.

[140] J. G. Abraldes, Y. Iwakiri, M. Loureiro-Silva, O. Haq, W. C. Sessa, and R. J. Groszmann, "Mild increases in portal pressure upregulate vascular endothelial growth factor and endothelial nitric oxide synthase in the intestinal microcirculatory bed, leading to a hyperdynamic state," American Journal of Physiology-Gastrointestinal and Liver Physiology, vol. 290, no. 5, pp. G980-G987, 2006.

[141] J. I. Greenberg, D. J. Shields, S. G. Barillas et al., "A role for VEGF as a negative regulator of pericyte function and vessel maturation," Nature, vol. 456, no. 809, p. 813, 2009.

[142] T. A. Wynn, "Cellular and molecular mechanisms of fibrosis," Journal of Pathology, vol. 214, no. 2, pp. 199-210, 2008.

[143] M. J. Goumans and C. Mummery, "Functional analysis of the TGF $\beta$ receptor/Smad pathway through gene ablation in mice," International Journal of Developmental Biology, vol. 44, no. 3, pp. 253-265, 2000.

[144] M. J. Goumans, Z. Liu, and P. Ten Dijke, "TGF- $\beta$ signaling in vascular biology and dysfunction," Cell Research, vol. 19, no. 1, pp. 116-127, 2009.

[145] V. V. Orlova, Z. Liu, M. J. Goumans et al., "Controlling angiogenesis by two unique TGF-beta type I receptor signaling pathways," Histology and Histopathology, vol. 26, no. 9, pp. 1219-1230, 2011.

[146] M. S. Pepper, "Transforming growth factor-beta: vasculogenesis, angiogenesis, and vessel wall integrity," Cytokine and Growth Factor Reviews, vol. 8, no. 1, pp. 21-43, 1997.
[147] Y. T. Lai, K. B. Beason, G. P. Brames et al., "Activin receptor-like kinase 2 can mediate atrioventricular cushion transformation," Developmental Biology, vol. 222, no. 1, pp. $1-11,2000$.

[148] H. M. Arthur, J. Ure, A. J. H. Smith et al., "Endoglin, an ancillary TGF $\beta$ receptor, is required for extraembryonic angiogenesis and plays a key role in heart development," Developmental Biology, vol. 217, no. 1, pp. 42-53, 2000.

[149] F. Lebrin, M. J. Goumans, L. Jonker et al., "Endoglin promotes endothelial cell proliferation and TGF- $\beta$ /ALK1 signal transduction," EMBO Journal, vol. 23, no. 20, pp. 4018-4028, 2004.

[150] N. Rudini, A. Felici, C. Giampietro et al., "VE-cadherin is a critical endothelial regulator of TGF- $\beta$ signalling," $E M B O$ Journal, vol. 27, no. 7, pp. 993-1004, 2008.

[151] E. M. Zeisberg, O. Tarnavski, M. Zeisberg et al., "Endothelialto-mesenchymal transition contributes to cardiac fibrosis," Nature Medicine, vol. 13, no. 8, pp. 952-961, 2007.

[152] E. M. Zeisberg, S. E. Potenta, H. Sugimoto, M. Zeisberg, and R. Kalluri, "Fibroblasts in kidney fibrosis emerge via endothelial-to-mesenchymal transition," Journal of the American Society of Nephrology, vol. 19, no. 12, pp. 2282-2287, 2008.

[153] M. J. Goumans, A. J. van Zonneveld, and P. ten Dijke, "Transforming growth factor $\beta$-induced endothelial-tomesenchymal transition: a switch to cardiac fibrosis?" Trends in Cardiovascular Medicine, vol. 18, no. 8, pp. 293-298, 2008.

[154] T. Kisseleva and D. A. Brenner, "Hepatic stellate cells and the reversal of fibrosis," Journal of Gastroenterology and Hepatology, vol. 21, supplement 3, pp. S84-S87, 2006.

[155] G. Tiegs and A. W. Lohse, "Immune tolerance: what is unique about the liver," Journal of Autoimmunity, vol. 34, no. 1, pp. $1-6,2010$.

[156] S. Magder, J. Neculcea, V. Neculcea, and R. Sladek, "Lipopolysaccharide and TNF- $\alpha$ produce very similar changes in gene expression in human endothelial cells," Journal of Vascular Research, vol. 43, no. 5, pp. 447-461, 2006.

[157] T. Kisseleva, L. Song, M. Vorontchikhina, N. Feirt, J. Kitajewski, and C. Schindler, "NF- $\kappa$ B regulation of endothelial cell function during LPS-induced toxemia and cancer," Journal of Clinical Investigation, vol. 116, no. 11, pp. 2955-2963, 2006.

[158] Z. Sun, A. S. Klein, S. Radaeva et al., "In vitro interleukin6 treatment prevents mortality associated with fatty liver transplants in rats," Gastroenterology, vol. 125, no. 1, pp. 202215, 2003.

[159] B. Gao, "Therapeutic potential of interleukin-6 in preventing obesity- and alcohol-associated fatty liver transplant failure," Alcohol, vol. 34, no. 1, pp. 59-65, 2004.

[160] A. M. Miller, N. Horiguchi, W. I. Jeong, S. Radaeva, and B. Gao, "Molecular mechanisms of alcoholic liver disease: innate immunity and cytokines," Alcoholism, vol. 35, no. 5, pp. 787-793, 2011.

[161] A. M. Miller, H. Wang, O. Park et al., "Anti-inflammatory and anti-apoptotic roles of endothelial cell STAT3 in alcoholic liver injury," Alcoholism, vol. 34, no. 4, pp. 719-725, 2010.

[162] N. F. Larusso and T. V. Masyuk, "The role of cilia in the regulation of bile flow," Digestive Diseases, vol. 29, no. 1, pp. 6-12, 2011.

[163] A. L. Means, Y. Xu, A. Zhao, K. C. Ray, and G. Gu, "A CK19CreERT knockin mouse line allows for conditional DNA recombination in epithelial cells in multiple endodermal organs," Genesis, vol. 46, no. 6, pp. 318-323, 2008.

[164] T. Kisseleva, E. Gigante, and D. A. Brenner, "Recent advances in liver stem cell therapy," Current Opinion in Gastroenterology, vol. 26, no. 4, pp. 395-402, 2010. 
[165] K. Harada, S. Shimoda, Y. Sato, K. Isse, H. Ikeda, and Y. Nakanuma, "Periductal interleukin-17 production in association with biliary innate immunity contributes to the pathogenesis of cholangiopathy in primary biliary cirrhosis," Clinical and Experimental Immunology, vol. 157, no. 2, pp. 261-270, 2009.

[166] M. Penz-Osterreicher, C.H. Osterreicher, and M. Trauner, "Fibrosis in autoimmune and cholestatic liver disease," Best Practice and Research, vol. 25, no. 2, pp. 245-258, 2011.

[167] A. Omenetti, L. Yang, Y. X. Li et al., "Hedgehog-mediated mesenchymal-epithelial interactions modulate hepatic response to bile duct ligation," Laboratory Investigation, vol. 87, no. 5, pp. 499-514, 2007.

[168] A. Omenetti, A. Porrello, Y. Jung et al., "Hedgehog signaling regulates epithelial-mesenchymal transition during biliary fibrosis in rodents and humans," Journal of Clinical Investigation, vol. 118, no. 10, pp. 3331-3342, 2008.

[169] D. Scholten, C. H. Österreicher, A. Scholten et al., "Genetic labeling does not detect epithelial-to-mesenchymal transition of cholangiocytes in liver fibrosis in mice," Gastroenterology, vol. 139, no. 3, pp. 987-998, 2010.

[170] A. S. Chu, R. Diaz, J. J. Hui et al., "Lineage tracing demonstrates no evidence of cholangiocyte epithelial-to-mesenchymal transition in murine models of hepatic fibrosis," Hepatology, vol. 53, no. 5, pp. 1685-1695, 2011.

[171] X. M. Chen, P. L. Splinter, S. P. O'Hara, and N. F. LaRusso, "A cellular micro-RNA, let-7i, regulates toll-like receptor 4 expression and contributes to cholangiocyte immune responses against Cryptosporidium parvum infection," Journal of Biological Chemistry, vol. 282, no. 39, pp. 28929-28938, 2007.

[172] S. P. O’Hara, P. L. Splinter, C. E. Trussoni, G. B. Gajdos, P. N. Lineswala, and N. F. LaRusso, "Cholangiocyte N-Ras protein mediates lipopolysaccharide-induced interleukin 6 secretion and proliferation," Journal of Biological Chemistry, vol. 286, no. 35, pp. 30352-30360, 2011.

[173] J. P. Iredale, "Models of liver fibrosis: exploring the dynamic nature of inflammation and repair in a solid organ," Journal of Clinical Investigation, vol. 117, no. 3, pp. 539-548, 2007.

[174] A. Geerts, "History, heterogeneity, developmental biology, and functions of quiescent hepatic stellate cells," Seminars in Liver Disease, vol. 21, no. 3, pp. 311-335, 2001.

[175] B. D. Sachs, G. S. Baillie, J. R. McCall et al., "p75 neurotrophin receptor regulates tissue fibrosis through inhibition of plasminogen activation via a PDE4/cAMP/PKA pathway," Journal of Cell Biology, vol. 177, no. 6, pp. 1119$1132,2007$.

[176] T. J. Kendall, S. Hennedige, R. L. Aucott et al., "P75 neurotrophin receptor signaling regulates hepatic myofibroblast proliferation and apoptosis in recovery from rodent liver fibrosis," Hepatology, vol. 49, no. 3, pp. 901-910, 2009.

[177] H. Senoo, N. Kojima, and M. Sato, "Vitamin A-storing cells (Stellate Cells)," Vitamins and Hormones, vol. 75, pp. 131159, 2007.

[178] R. Bataller, R. F. Schwabe, Y. H. Choi et al., "NADPH oxidase signal transduces angiotensin II in hepatic stellate cells and is critical in hepatic fibrosis," Journal of Clinical Investigation, vol. 112, no. 9, pp. 1383-1394, 2003.

[179] F. Winau, G. Hegasy, R. Weiskirchen et al., "Ito cells are liver-resident antigen-presenting cells for activating $\mathrm{T}$ cell responses," Immunity, vol. 26, no. 1, pp. 117-129, 2007.

[180] K. Asahina, S. Y. Tsai, P. Li et al., "Mesenchymal origin of hepatic stellate cells, submesothelial cells, and perivascular mesenchymal cells during mouse liver development," Hepatology, vol. 49, no. 3, pp. 998-1011, 2009.
[181] N. Sanderson, V. Factor, P. Nagy et al., "Hepatic expression of mature transforming growth factor $\beta 1$ in transgenic mice results in multiple tissue lesions," Proceedings of the National Academy of Sciences of the United States of America, vol. 92, no. 7, pp. 2572-2576, 1995.

[182] B. Schnabl, Y. O. Kweon, J. P. Frederick, X. F. Wang, R. A. Rippe, and D. A. Brenner, "The role of Smad3 in mediating mouse hepatic stellate cell activation," Hepatology, vol. 34, no. 1, pp. 89-100, 2001.

[183] S. Dooley, J. Hamzavi, K. Breitkopf et al., "Smad7 prevents activation of hepatic stellate cells and liver fibrosis in rats," Gastroenterology, vol. 125, no. 1, pp. 178-191, 2003.

[184] J. Hamzavi, S. Ehnert, P. Godoy et al., "Disruption of the Smad7 gene enhances CCI4-dependent liver damage and fibrogenesis in mice," Journal of Cellular and Molecular Medicine, vol. 12, no. 5B, pp. 2130-2144, 2008.

[185] E. Wiercinska, L. Wickert, B. Denecke et al., "Id1 Is a critical mediator in TGF- $\beta$-induced transdifferentiation of rat hepatic stellate cells," Hepatology, vol. 43, no. 5, pp. 10321041, 2006

[186] G. Fibbi, M. Pucci, S. D’Alessio et al., “Transforming growth factor beta-1 stimulates invasivity of hepatic stellate cells by engagement of the cell-associated fibrinolytic system," Growth Factors, vol. 19, no. 2, pp. 87-100, 2001.

[187] C. Yang, M. Zeisberg, B. Mosterman et al., "Liver fibrosis: insights into migration of hepatic stellate cells in response to extracellular matrix and growth factors," Gastroenterology, vol. 124, no. 1, pp. 147-159, 2003.

[188] T. Maehama and J. E. Dixon, "The tumor suppressor, PTEN/MMAC1, dephosphorylates the lipid second messenger, phosphatidylinositol 3,4,5-trisphosphate," Journal of Biological Chemistry, vol. 273, no. 22, pp. 13375-13378, 1998.

[189] S. Reif, A. Lang, J. N. Lindquist et al., "The role of focal adhesion kinase-phosphatidylinositol 3-kinase-Akt signaling in hepatic stellate cell proliferation and type I collagen expression," Journal of Biological Chemistry, vol. 278, no. 10, pp. 8083-8090, 2003.

[190] M. Takashima, C. J. Parsons, K. Ikejima, S. Watanabe, E. S. White, and R. A. Rippe, "The tumor suppressor protein PTEN inhibits rat hepatic stellate cell activation," Journal of Gastroenterology, vol. 44, no. 8, pp. 847-855, 2009.

[191] M. Pinzani and F. Marra, "Cytokine receptors and signaling in hepatic stellate cells," Seminars in Liver Disease, vol. 21, no. 3, pp. 397-416, 2001.

[192] F. Marra, M. C. Arrighi, M. Fazi et al., "Extracellular signalregulated kinase activation differentially regulates plateletderived growth factor's actions in hepatic stellate cells, and is induced by in vivo liver injury in the rat," Hepatology, vol. 30, no. 4, pp. 951-958, 1999.

[193] J. Li, C. Yen, D. Liaw et al., "PTEN, a putative protein tyrosine phosphatase gene mutated in human brain, breast, and prostate cancer," Science, vol. 275, no. 5308, pp. 19431947, 1997.

[194] Y. G. Kwak, C. H. Song, H. K. Yi et al., "Involvement of PTEN in airway hyperresponsiveness and inflammation in bronchial asthma," Journal of Clinical Investigation, vol. 111, no. 7, pp. 1083-1092, 2003.

[195] E. S. White, V. J. Thannickal, S. L. Carskadon et al., "Integrin $\alpha 4 \beta 1$ regulates migration across basement membranes by lung fibroblasts: a role for phosphatase and tensin homologue deleted on chromosome 10," American Journal of Respiratory and Critical Care Medicine, vol. 168, no. 4, pp. 436-442, 2003.

[196] T. Pap, J. K. Franz, K. M. Hummel, E. Jeisy, R. Gay, and S. Gay, "Activation of synovial fibroblasts in rheumatoid arthritis: 
lack of expression of the tumour suppressor PTEN at sites of invasive growth and destruction," Arthritis Research, vol. 2, no. 1, pp. 59-64, 2000.

[197] W. Cui, K. Matsuno, K. Iwata et al., "NOX1/nicotinamide adenine dinucleotide phosphate, reduced form (NADPH) oxidase promotes proliferation of stellate cells and aggravates liver fibrosis induced by bile duct ligation," Hepatology, vol. 54, pp. 949-958, 2011.

[198] C. H. Heldin and B. Westermark, "Mechanism of action and in vivo role of platelet-derived growth factor," Physiological Reviews, vol. 79, no. 4, pp. 1283-1316, 1999.

[199] M. Pinzani and J. MacIas-Barragan, "Update on the pathophysiology of liver fibrosis," Expert Review of Gastroenterology and Hepatology, vol. 4, no. 4, pp. 459-472, 2010.

[200] D. A. Mann and D. E. Smart, "Transcriptional regulation of hepatic stellate cell activation," Gut, vol. 50, no. 6, pp. 891896, 2002.

[201] A. M. Elsharkawy, M. C. Wright, R. T. Hay et al., "Persistent activation of nuclear factor- $\kappa \mathrm{B}$ in cultured rat hepatic stellate cells involves the induction of potentially novel rel-like factors and prolonged changes in the expression of $\mathrm{I} \kappa \mathrm{B}$ family proteins," Hepatology, vol. 30, no. 3, pp. 761-769, 1999.

[202] J. Mann and D. A. Mann, "Transcriptional regulation of hepatic stellate cells," Advanced Drug Delivery Reviews, vol. 61, no. 7-8, pp. 497-512, 2009.

[203] A. Hosui, A. Kimura, D. Yamaji, B. M. Zhu, R. Na, and L. Hennighausen, "Loss of STAT5 causes Liver fbrosis and cancer development through increased TGF- $\beta$ and STAT3 activation," Journal of Experimental Medicine, vol. 206, no. 4, pp. 819-831, 2009.

[204] H. Ogata, T. Chinen, T. Yoshida et al., "Loss of SOCS3 in the liver promotes fibrosis by enhancing STAT3-mediated TGF$\beta 1$ production," Oncogene, vol. 25, no. 17, pp. 2520-2530, 2006.

[205] N. K. Saxena, M. A. Titus, X. Ding et al., "Leptin as a novel profibrogenic cytokine in hepatic stellate cells: mitogenesis and inhibition of apoptosis mediated by extracellular regulated kinase (Erk) and Akt phosphorylation," FASEB Journal, vol. 18, no. 13, pp. 1612-1614, 2004.

[206] S. S. Choi, W. K. Syn, G. F. Karaca et al., "Leptin promotes the myofibroblastic phenotype in hepatic stellate cells by activating the Hedgehog pathway," Journal of Biological Chemistry, vol. 285, no. 47, pp. 36551-36560, 2010.

[207] Y. Liu, J. Brymora, H. Zhang et al., "Leptin and acetaldehyde synergistically promotes $\alpha$ SMA expression in hepatic stellate cells by an interleukin6-dependent mechanism," Alcoholism, vol. 35, no. 5, pp. 921-928, 2011.

[208] B. Tuchweber, A. Desmoulière, M. L. Bochaton-Piallat, L. Rubbia-Brandt, and G. Gabbiani, "Proliferation and phenotypic modulation of portal fibroblasts in the early stages of cholestatic fibrosis in the rat," Laboratory Investigation, vol. 74, no. 1, pp. 265-278, 1996.

[209] C. Guyot, S. Lepreux, C. Combe et al., "Hepatic fibrosis and cirrhosis: the (myo)fibroblastic cell subpopulations involved," International Journal of Biochemistry and Cell Biology, vol. 38, no. 2, pp. 135-151, 2006.

[210] N. Kinnman, C. Francoz, V. Barbu et al., "The myofibroblastic conversion of peribiliary fibrogenic cells distinct from hepatic stellate cells is stimulated by platelet-derived growth factor during liver fibrogenesis," Laboratory Investigation, vol. 83, no. 2, pp. 163-173, 2003.

[211] M. Parola, F. Marra, and M. Pinzani, "Myofibroblast-like cells and liver fibrogenesis: emerging concepts in a rapidly moving scenario," Molecular Aspects of Medicine, vol. 29, no. 1-2, pp. 58-66, 2008.
[212] R. G. Wells, E. Kruglov, and J. A. Dranoff, "Autocrine release of TGF- $\beta$ by portal fibroblasts regulates cell growth," FEBS Letters, vol. 559, no. 1-3, pp. 107-110, 2004.

[213] T. Knittel, D. Kobold, B. Salle et al., "Rat liver myofibroblasts and hepatic stellate cells: different cell populations of the fibroblast lineage with fibrogenic potential," Gastroenterology, vol. 117, no. 5, pp. 1205-1221, 1999.

[214] L. Tang, Y. Tanaka, F. Marumo, and C. Sato, "Phenotypic change in portal fibrosis in biliary fibrosis," Liver, vol. 14, no. 2, pp. 76-82, 1994.

[215] N. Bosselut, C. Housset, P. Marcelo et al., "Distinct proteomic features of two fibrogenic liver cell populations: hepatic stellate cells and portal myofibroblasts," Proteomics, vol. 10, no. 5, pp. 1017-1028, 2010.

[216] J. A. Dranoff and R. G. Wells, "Portal fibroblasts: underappreciated mediators of biliary fibrosis," Hepatology, vol. 51, no. 4, pp. 1438-1444, 2010.

[217] J. Dudas, T. Mansuroglu, D. Batusic, B. Saile, and G. Ramadori, "Thy-1 is an in vivo and in vitro marker of liver myofibroblasts," Cell and Tissue Research, vol. 329, no. 3, pp. 503-514, 2007.

[218] M. I. Yovchev, J. Zhang, D. S. Neufeld, P. N. Grozdanov, and M. D. Dabeva, "Thymus cell antigen-1-expressing cells in the oval cell compartment," Hepatology, vol. 50, no. 2, pp. 601611, 2009.

[219] S. J. Forbes and M. Parola, "Liver fibrogenic cells," Best Practice and Research, vol. 25, no. 2, pp. 207-217, 2011.

[220] T. Knittel, D. Kobold, F. Piscaglia et al., "Localization of liver myofibroblasts and hepatic stellate cells in normal and diseased rat livers: distinct roles of (myo-)fibroblast subpopulations in hepatic tissue repair," Histochemistry and Cell Biology, vol. 112, no. 5, pp. 387-401, 1999.

[221] J. Dudas, T. Mansuroglu, D. Batusic, and G. Ramadori, “Thy1 is expressed in myofibroblasts but not found in hepatic stellate cells following liver injury.," Histochemistry and cell biology, vol. 131, no. 1, pp. 115-127, 2009.

[222] S. J. Forbes and M. Parola, "Liver fibrogenic cells," Best Practice and Research, vol. 25, no. 2, pp. 207-217, 2011.

[223] I. Matsuura, K. N. Chiang, C. Y. Lai et al., "Pin1 promotes transforming growth factor- $\beta$-induced migration and invasion," Journal of Biological Chemistry, vol. 285, no. 3, pp. 1754-1764, 2010. 


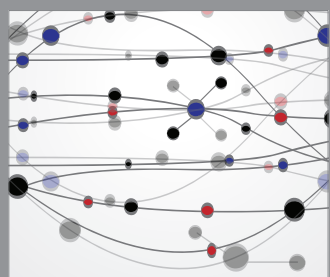

The Scientific World Journal
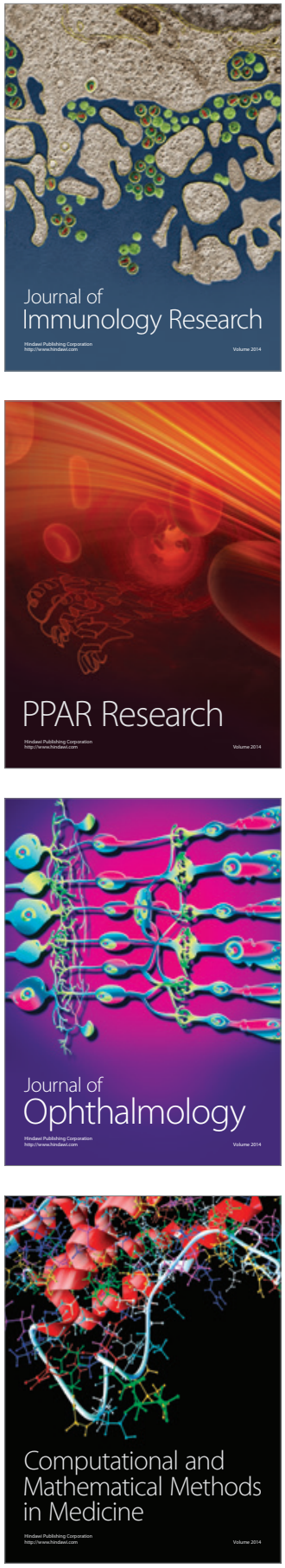

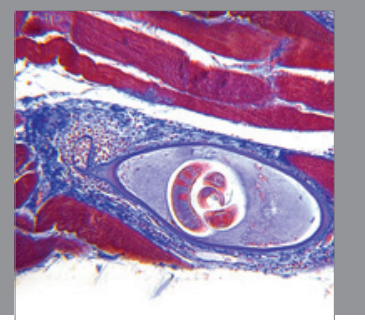

Gastroenterology

Research and Practice
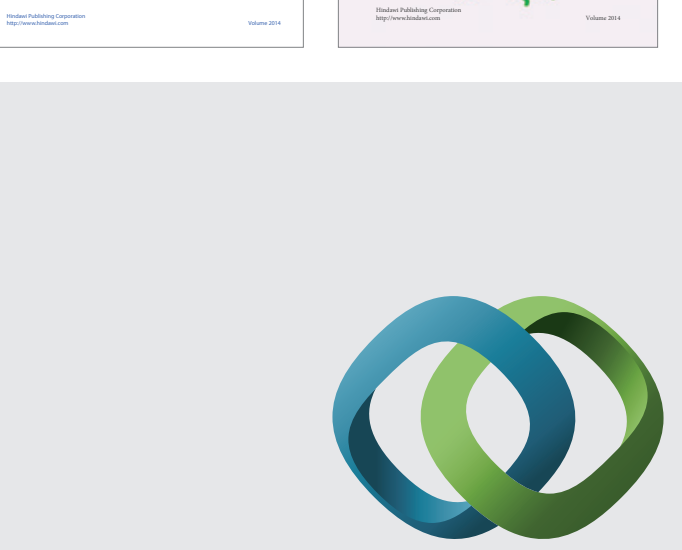

\section{Hindawi}

Submit your manuscripts at

http://www.hindawi.com
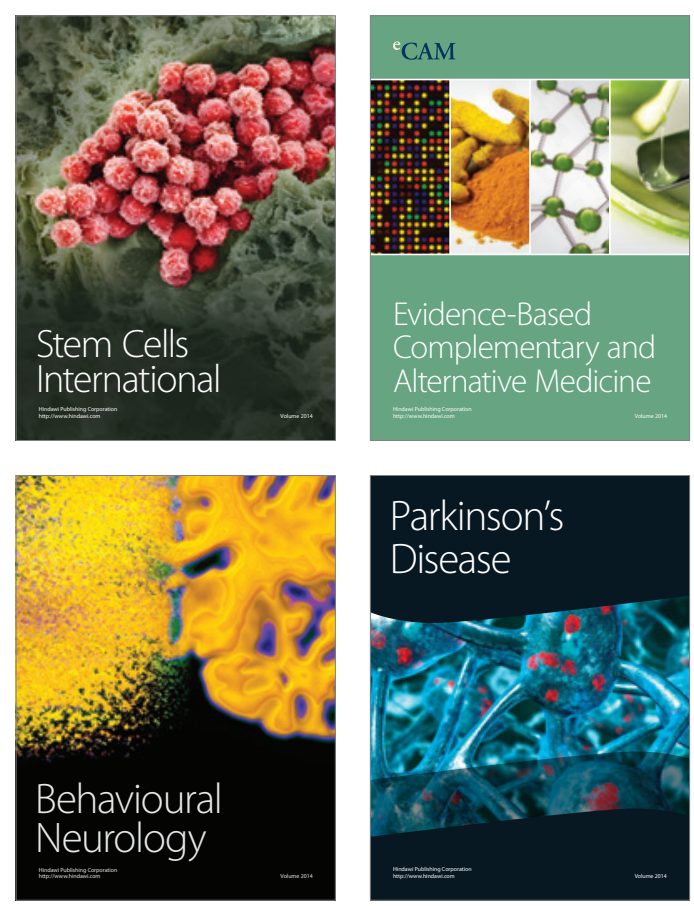

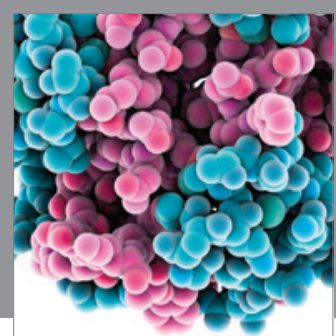

Journal of
Diabetes Research

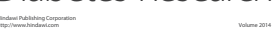

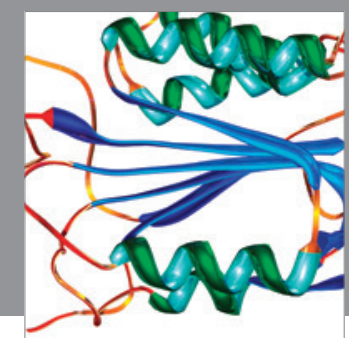

Disease Markers
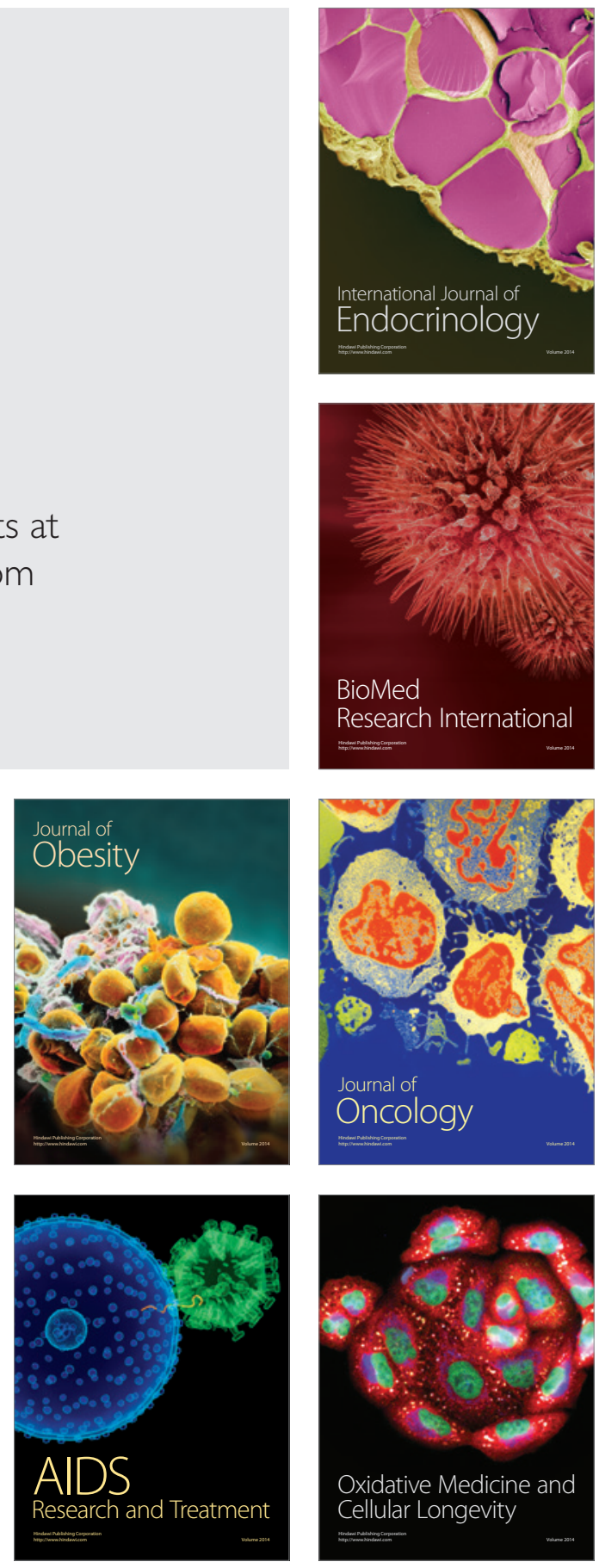